

\section{DISCLAIMER}

This report was prepared as an account of work sponsored by an agency of the United States Government. Neither the United States Government nor any agency Thereof, nor any of their employees, makes any warranty, express or implied, or assumes any legal liability or responsibility for the accuracy, completeness, or usefulness of any information, apparatus, product, or process disclosed, or represents that its use would not infringe privately owned rights. Reference herein to any specific commercial product, process, or service by trade name, trademark, manufacturer, or otherwise does not necessarily constitute or imply its endorsement, recommendation, or favoring by the United States Government or any agency thereof. The views and opinions of authors expressed herein do not necessarily state or reflect those of the United States Government or any agency thereof. 


\section{DISCLAIMER}

Portions of this document may be illegible in electronic image products. Images are produced from the best available original document. 


\section{DISCLAIMER}

"This book was prepared as an account of work sponsored by an agency of the United States Government. Neither the IInited States Government nor any agency thereof, nor any of their employees, makes any warranty, express or implied, or assumes any legal liahility or iespunslbillty for the accuracy, completeness, or usefulness of any information, apparatuo, product, or process disclosed, or represents that its use would nnt infringe privatoly owned rights. Keference herein to any specific commercial product, process, or service by trade name, trademark, manufacturer, or otherwise, does not necessarily constitute or imply its endorsement, recommendation, or favoring by the United States Government or any agency thereof. The views and opinions of authors expressed herein do not necessarily state or reflect those of the United States Government or any agency thereof."

This report has been reproduced directly from the best available copy.

Available from the National Technical Information Service, U. S. Department of Commerce, Springfield, Virginia 22161.

Price: Printel Copy A04 Microfiche A01 


\title{
CdSIAs $_{2}$ THIN FILMS FOR SOLAR CELL APPLICATIONS
}

FINAL REPORT: $4 / 9 / 79-4 / 8 / 80$

L. C. Burton

L. H. Slack

June, 1980

\author{
Virginia Polytechnic Institute and State University \\ Blacksburg, VA 24061
}

Work performed under Department of Energy Contract DE-AC02-79ET23007 


\section{ABSTRACT}

Compounds of Cd-Si-As required for sputtering targets and evaporation charges were synthesized by direct fusion. These include CdSiAs ${ }_{2}, \mathrm{Cd}_{3} \mathrm{As}_{2}$, $\mathrm{CdAs}_{2}$ and SiAs. Polycrystalline ingots of $\mathrm{CdSiAs}_{2}$ were found to be porous, with the chalcopyrite structure, and with minor amounts of other phases such as $\mathrm{CdAs}_{2}$, SiAs, As and $\mathrm{Cd}_{3} \mathrm{As}_{2}$.

Sputtered films were formed in a single target RF system. A homogeneous CdSiAs ${ }_{2}$ target was initially used, followed by composite targets consisting of $\mathrm{CdAs}_{2}+\mathrm{Si}$. Films from the 1atter targets were superior to the others and were more extensively studied. As deposited films were amorphous, off stoichiometry, with resistivities over $10^{8} \Omega-\mathrm{cm}$ and band gaps of $\sim 1.4 \mathrm{ev}$. Subsequent reactive heat treatments in the $515^{\circ}-615^{\circ} \mathrm{C}$ range resulted in crystalline films, resistivities of $1-10 \Omega \mathrm{cm}, \mathrm{CdSiAs}_{2}$ compositions within $1 \%$ of stoichiometry, energy gap of $\sim 1.55 \mathrm{ev,} \mathrm{absorption} \mathrm{coefficient} \mathrm{of}$ $2 \times 10^{4} \mathrm{~cm}^{-1}$ at $0.6 \mu \mathrm{m}$, but with poor mechanical properties (mainly cracking). A $\mathrm{Ta} / \mathrm{SiO}_{2}$ substrate proved to be the best for these films.

Thermal evaporation studies of CdSiAs $_{2}$ established that effusion is preferential toward Cd between 570 and $710^{\circ} \mathrm{C}$, and toward As in the 710$1010^{\circ} \mathrm{C}$ range. All films resulting from $\mathrm{CdAs}_{2}$ charges were found to be $\mathrm{Cd}$ deflcleut. For thesc reasons, over the 1.ast 6 months of the program, only sputtered films were studied further.

Preliminary $\mathrm{CdSiAs}_{2} / \mathrm{CdS}$ junctions were formed on bulk and sputtered CdSiAs $_{2}$. The bulk junctions produced photoresponse up to $0.25 \mathrm{v}$ and several $\mu \mathrm{A}$. The thin film junctions were rectifying, but generated insignificant photoresponse, apparently due to the poor properties of the CdSIAs $\mathrm{Ftlms}_{2}$

A new multi-target sputtering unit (Perkin-Elmer Mod 2400 8-J) was 1nstalled toward the end of the program, although no Cd-Si-As films were made. by $4 / 8 / 80$ (conclusion of contract.) 
ABSTRACT $\quad$ • $\quad$ •

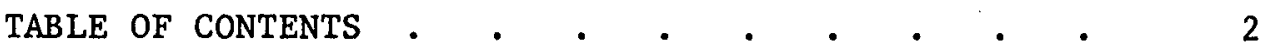

1. INIRODUCTION

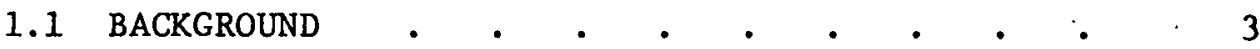

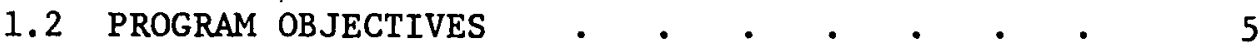

2. IECHNICAL NARRATIVE . . . . . . . . . . . 6

2.1 BULK SYNTHESIS . . . . . . . . . . 66

2.2 SPUTTERED FILMS . . . . . . . . . . . . . 16

2.3 EVAPORATED FILMS . . . . . . . . . 50

2.4 HETEROJUNCTION FABRICATION . . . . . . . 62

3. REFERENCES . . . . . . . . . . . 66

4. RESEARCH CONTRIBUTORS . . . . . . . . . . . 67

5. DISTRIBUTION LIST . . . . . . . • . . . 68 


\section{INTRODUCTION}

Th1s is the Final Repurt for DOE Contract No. DE AC04 79ET23007, "CdSiAs 2 Thin Films for Solar Cell Applications".

\subsection{Background}

The major reasons for studying CdSIAs $_{2}$ as a photovoltaic absorbing materlal were reviewed in the First Quarterly Report. (1) The following facts are significant in this regard:

a) The CdSiAs 2 band gap is direct and close to the predicted conversion efficiency maximum;

b) The lattice mismatch with CdS is less than $0.6 \%$, making a heterojunction with this compound feasible;

c) The wide gap of CdS allows the backwall configuration to also be Investigated;

d) Electron affinity values indicate that there is no energy spike at the interface;

e) For possible long term terrestrial applications, avallability of materials should not pose a problem ${ }^{(2)}$, and several less expensive technologles exist for CdS thin film formation.

Using tabulated parameters, a preliminary band diagram was constructed for the $\mathrm{CdSiAs}_{2} / \mathrm{CdS}$ heterojunction, with assumed carrier concentrations of $10^{16} \mathrm{~cm}^{-3}$ and $10^{18} \mathrm{~cm}^{-3}$ for ${\mathrm{CdS} 1 A s_{2}}_{2}$ and $\mathrm{CdS}$ respectively. This diagram is shown in Figure 1. Key points here are that an alding electric field exists in the CdSiAs 2 absorber, and no interfacial spike exists in the conduction band.

Thus, on paper, $\operatorname{CdSiAs}_{2}$ as a potential photovoltaic absorber, especially when combined with a CdS collector, appears attractive. 
$\mathrm{Cd} \mathrm{SiAs} 2 \quad \mathrm{CdS}$

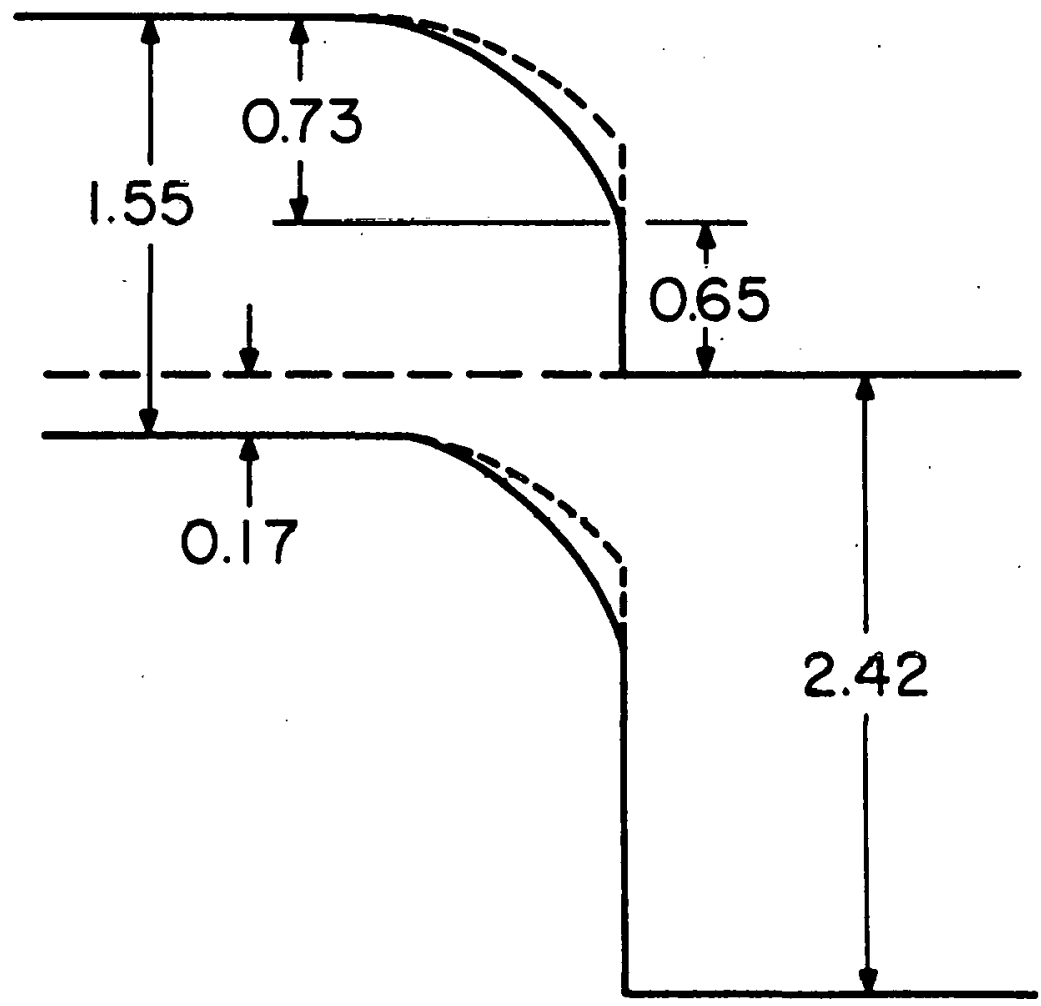

Figure 1. Theoretical CdS/CdSiAs 2 Band Diagram 


\subsection{Program Objectives}

The mafor objective of the program was the formation of CdSiAs, thin films suitable for heterojunction solar cells. The tasks (3) are summarlzed below, and research related to them is reviewed in the followIng section.

\section{Task 1: Thin Film Growth}

Task 1.1 - Preparation of bulk materfal for sputtering and evaporation. This includes $\mathrm{CdSiAs}_{2}, \mathrm{CdAs}_{2}, \mathrm{Cd}_{3} \mathrm{As}_{2}, \mathrm{SiAs}$ and $\mathrm{SiAs}_{2}$ as required to form targets and charges.

Task 1.2 - Sputter deposition of CdSiAs $_{2}$ films. Single and mult1target techniques will be used.

Task 1.3 - Evaporation of CdSiAs $_{2}$ films. Single and multi-source techniques will be used.

Task 1.4 - Film optimization.

\section{Task 2: Film Characterization}

Task 2.1 - Mechanical and electrical film characterization, including morphology, x-ray diffraction, average composition, composition profiles, resistivity and mob1lity measurements.

Task 2.2 - Wavelength dependence of absorption coefficlent between 0.4 and $1.0 \mu \mathrm{m}$.

Task 2.3 - Minority carrier diffusion length measurement.

Task 2.4 - Determine film thickness for absorption of $50 \%$ and $90 \%$ of Incident light as function of wavelength; optimize film thickness.

\section{Task 3: Solar Celi Fabrication}

Task 3.1 - Fabrication of $\operatorname{CdS} \mathrm{As}_{2} /$ CdS thin film heterojunction solar cells, using CdS as the collector material.

Task 3.2 - Evaluation of $\operatorname{CdSIAs}_{2}$ /CdS solar cells by taking I-V curves under solar or simulated irradiation. 


\section{TECHNICAL NARRATIVE}

The discussion below is divided into four areas: Bulk Synthesis (2.1), Sputtered Films (2.2), Evaporated Films (2.3) and Heterojunction Formation (2.4). Experimental techniques used, characterization, results and conclusions will be discussed in each case.

\subsection{Bulk Synthesis}

This was the initial task that was addressed, and was discussed in some detail in the First Quarterly Report ${ }^{(1)}$.

CdSiAs $_{2}$ bulk material was required for subsequent tasks, namely for sputtering targets and evaporation charge. Polycrystalline CdSiAs 2 bulk (with crystallites up to several $\mathrm{mm}$ in length being obtained) were formed by direct fusion of the elements, in ampoules approximately $12 \mathrm{~cm} 10 \mathrm{ng}$. The ampoule was positioned vertically in a furnace such that the temperature at the upper end was in the range $650-850^{\circ} \mathrm{C}$. Temperature decreased down the ampoule. The SiAs pieces at the top of the ampoule floated on the $\mathrm{CdAs}_{x}$ and dissolved at a rate determined by the temperature. The diseolved siAs established a concentration gradient in the CdAs $x$ that drove diffusiou. The temperature gradient controlled the diffusion process. Super-saturation and crystallization of CdSiAs $_{2}$ occurred at the colder end of the ampnn1.e.

Subsequent to this formation process, different ampoules received different quenching and heat treatment operations. This was necessary due to the fact that the equilibrium melting behavior of CdSi $\mathrm{Co}_{2}$ is incongruert, thereby introducing compositional inhomogeneity into directly solidified Ingots from stoichiometric melts.

X-Ray Analysis

The $x$-ray diffraction data for CdSiAs ${ }_{2}$ ingots solidified from the melt 
indicated that $\mathrm{CdSiAs}_{2}$ was the major phase present. Subsequent heat treatments were found which reduced other phases to levels beyond detection via $x$-ray diffraction. Water, air and furnace quenchings were investigated, followed by heat treatments in certain cases.

$X$-ray data for a water quenched ingot is shown in Table 1. This ingot, as quenched, had a greater amount of CdSiAs $_{2}$ in the bottom section, with SiAs as a major phase at the top. A subsequent heat treatment at $825^{\circ} \mathrm{C}$ for 5 houro cllminated all phasp peaks from the pattern other than those of $\operatorname{CdSiAs}_{2} \cdot$

Table 2 shows $x$-ray data for a run which was water quenched from $950^{\circ} \mathrm{C}$ after soaking at $1050^{\circ} \mathrm{C}$. No peaks corresponding to material other than CdSiAs $_{2}$ could be found in this case.

Rapid air quenching of molten CdSiAs $_{2}$ onto a cooled metal plate was also effective in minimizing inhomogeneity. $\mathrm{SIAs}_{2} \mathrm{x}$-ray peaks were still detected however.

Electron Microprobe Analysis

Electron microprobe analyses of $\mathrm{CdSiAs}_{2}$ ingots located pockets of minor phase matertals in every 1ngot. Some ingots that had been heat treated had substantially fewer zones of phase separation from the $\mathrm{CdSIAs}_{2}{ }^{\circ}$ Table 3 lists samples with phases identified therein by electron microprobe. It can be seen that $\mathrm{CdAs}_{2}$, SiAs, As and $\mathrm{Cd}_{3} \mathrm{As}_{2}$ were the minor phase materlals. The solidification of the Cd-Si-As system is discussed shortly.

\section{Microscopy}

A photograph of a CdSiAs 2 chunk is shown in F1gure 2. The large crystals are ${\mathrm{CdS} I A s_{2}}_{2}$, as determined by mlcroprobe analysis. The chunk had broken off the parent ingot and is about $1 \mathrm{~cm}$. $10 \mathrm{ng}$. 
TABLE 1

X-Ray Diffraction Peak Positions $\left({ }^{\circ} 2 \theta\right)$ For Bulk CdSiAs ${ }_{2}$, Run 18

\begin{tabular}{|c|c|c|c|c|}
\hline Powder & $\begin{array}{l}\text { Bottom } \\
\text { of Ingot }\end{array}$ & $\begin{array}{l}\text { Top of } \\
\text { Ingot }\end{array}$ & $\begin{array}{c}\text { Top of } \\
\text { Ingot--HT }\end{array}$ & hke \\
\hline $\begin{array}{l}25.8 \\
27.0 \\
28.1 \\
28.9 \\
29.2 \\
30.0 \\
35.1 \\
42.6 \\
43.5 \\
44.4 \\
45.4\end{array}$ & $\begin{array}{r}25.8 \\
27.0 \\
28.9 \\
30.0 \\
35.1 \\
42.5 \\
43.4 \\
44.4 \\
45.4\end{array}$ & $\begin{array}{l}17.1 \\
19.8 \\
22.4 \\
25.8 \\
27.0 \\
28.2 \\
29.3 \\
30.0 \\
35.1 \\
39.3 \\
43.5 \\
45.4 \\
45.9 \\
47.8\end{array}$ & $\begin{array}{l}27.0 \\
28.9 \\
35.1 \\
42.5 \\
43.5 \\
44.4 \\
45.4 \\
47.1\end{array}$ & $\begin{array}{l}101 \\
112 \mathrm{Cd}_{3} \mathrm{As}_{2} \\
200 \mathrm{CdAs}_{2} \\
402 \mathrm{~S}_{1} \mathrm{As}^{2} \\
112 \\
220,004 \mathrm{Cd}_{3} \mathrm{As}_{2} \\
103 \\
003 \mathrm{~S} 1 \mathrm{As} \\
310,311 \mathrm{~S} 1 \mathrm{As} \\
211 \\
301 \mathrm{CdAs} 2 \\
213 \\
220 \\
105 \\
204 \\
313 \mathrm{~S} \mathrm{SAs} \\
301 \\
311 \mathrm{aCd}_{3} \mathrm{As}_{2}\end{array}$ \\
\hline
\end{tabular}




\section{TABLE 2}

X-Ray Diffraction Peak Positions

$\left({ }^{\circ} 2 \theta\right)$ For Bulk CdS1As 2 , Run 25, Water Quenched

\begin{tabular}{lrl}
\hline \hline $2 \theta$ & $I / I_{0}$ & hk $\ell$ \\
\hline 17.1 & 2 & 101 \\
27.0 & 100 & 112 \\
29.0 & 2 & 103 \\
35.1 & 15 & 211 \\
43.4 & 15 & 220 \\
45.4 & 30 & 204 \\
51.9 & 20 & 312 \\
55.3 & 5 & 116 \\
\hline
\end{tabular}


TABLE 3

Phase Identification in CdS1As 2 Ingots by Electron Microprobe Analysis

\begin{tabular}{ll}
\hline Ingot & Phases Ident1fled \\
\hline R71 & CdSiAs $_{2}, \mathrm{CdAs}_{2}, \mathrm{Cd}_{3} \mathrm{As}_{2}$ \\
R73 & $\operatorname{CdSiAs}_{2}, \mathrm{CdAs}_{2}, \mathrm{Cd}_{3} \mathrm{As}_{2}$ \\
R74 & CdSiAs $_{2}, \mathrm{CdAs}_{2}, \mathrm{Cd}_{3} \mathrm{As}_{2}, \mathrm{As}$ \\
ST-1 & CdSiAs $_{2}, \mathrm{CdNO}_{2}, \mathrm{CA}_{3} \mathrm{As}_{2}, 31 \mathrm{AL}$ \\
\hline
\end{tabular}




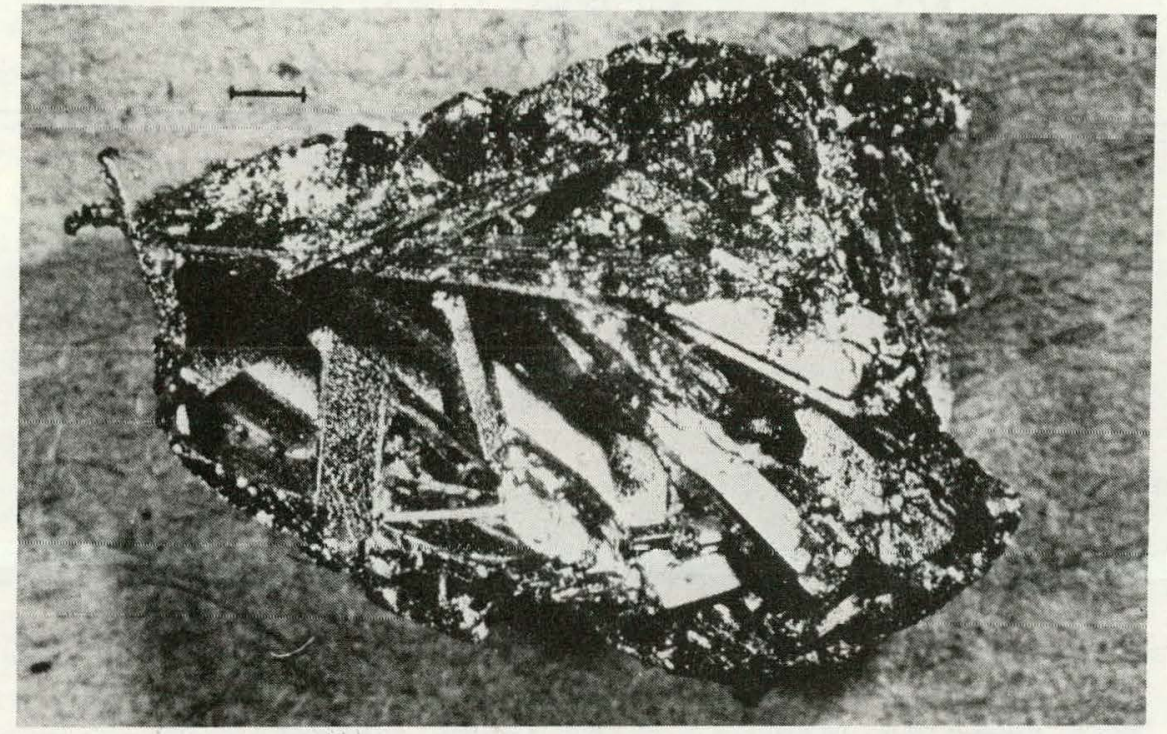

Figure 2. Photograph of a CdSiAs ${ }_{2}$ Chunk Showing Large CdSiAs 2 Crystals, Run 71 
Mechanical Quality

The CdSiAs, ${ }_{2}$ ingots had non-uniform morphology, some degree (varying) of phase separation, and extensive porosity. These factors all contributed to a very low quality mechanical characteristic. The major property of the material was its brittleness. With the non-uniform properties mentioned, the brittle material easily crumbled when stressed. Some samples did not form ingots but formed flakes. This effect occurred as a result of turbulence in the melt that was "frozen in" during quenching.

\section{Discussion}

We have been able to form near-stoichiometric samples of bulk CdSiAs ${ }_{2}$ by means of direct fusion of the elements. From these studies, the ternary system Cd-Si-As can be represented as shown in Figure $3 . \mathrm{CdSiAs}_{2}$ is the only ternary compound known to exist in the system ${ }^{(4)}$. A region of glass formation determined by Houserova and Hruby is represented. The compatibility triangle drawn is between $\mathrm{CdSiAs}_{2}, \mathrm{Cd}_{3} \mathrm{As}_{2}$ and SiAs. It is based on electron microprobe data of Table 3.

This compatability relationship is sub-solidus in nature and thereby holds for temperatures below $821^{\circ} \mathrm{C}$ for stoichiometric CdSiAs ${ }_{2}$ batches (with no loss of elements to the vapor phase). The starting composition of a $\mathrm{CdSiAs}_{2}$ batch is at the edge of the triangle. Losees of $\mathrm{As}_{4}$ vapor frum Llie melt change melt composition such that melt composition is located within the $\mathrm{Cd}_{3} \mathrm{As}_{2}-\mathrm{CdSiAs}_{2}$ - SiAs compatability triangle. Losses of both Cd and $\mathrm{As}_{4}$ vapors (often condensing as $\left(\mathrm{CdAs}_{2}\right.$ ) also cause a compositional change moving melt composition to the interior of the triangle.

The melt composition actually loses both $\mathrm{Cd}$ and $\mathrm{As}_{4}$ vapors thereby changing the effective melt composition to a point located in the $\mathrm{Cd}_{3} \mathrm{As}_{2}-$ CdSiAs2 - SiAs compatability triangle. The resulting melt solidifies into 


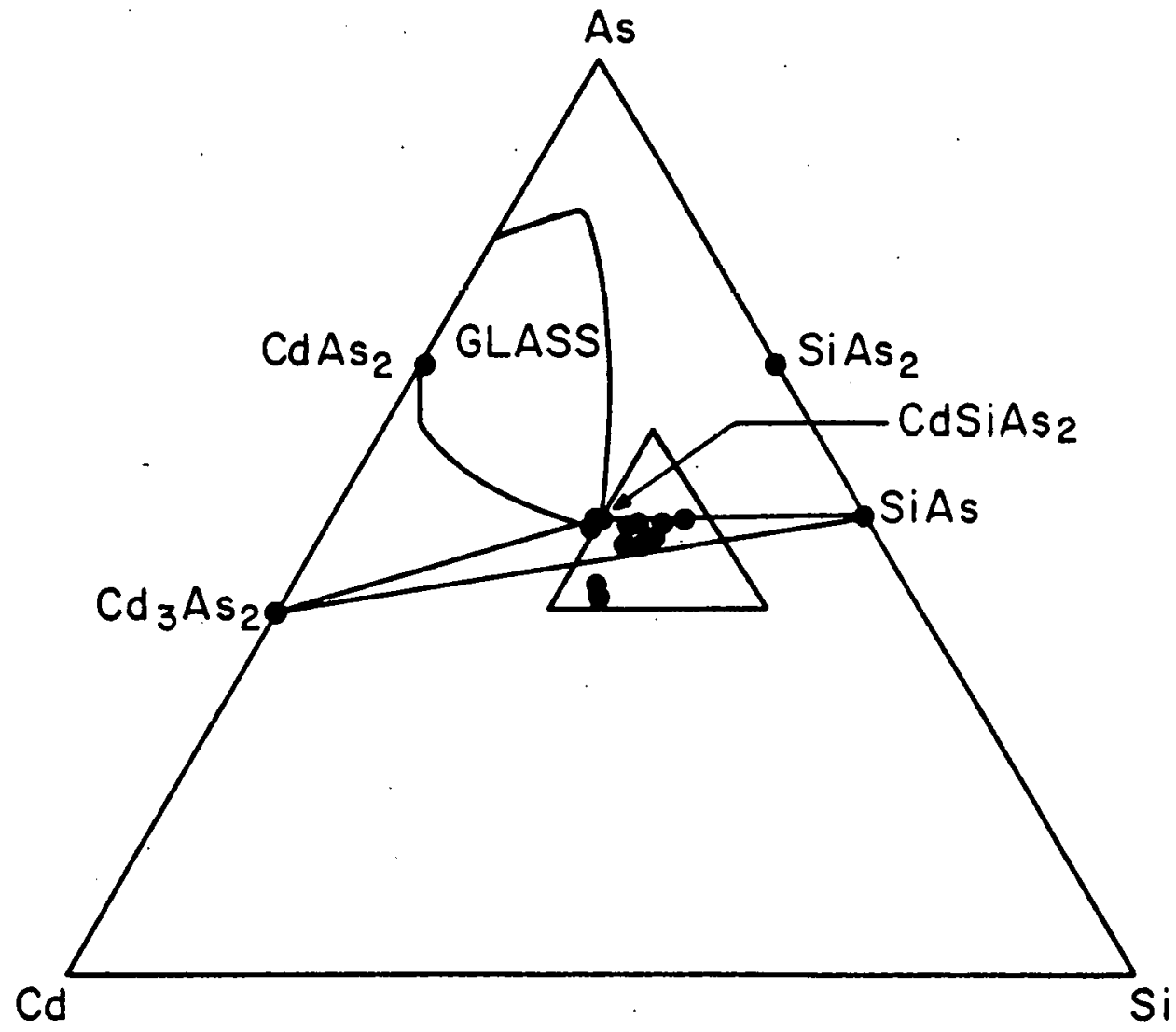

0

Figure 3. Diagram of the Cd-Si-As System Showing One Subsolidus Compatab111ty Relationship and the Glass Forming Region Determined by Houserova and Hruby ${ }^{4}$ 
three phases on cooling: SiAs $\left(\mathrm{T} \leq 1083^{\circ} \mathrm{C}\right)$ followed by $\mathrm{CdSiAs}_{2}\left(\mathrm{~T} \leq 944^{\circ} \mathrm{C}\right)$ and then by $\mathrm{Cd}_{3} \mathrm{As}_{2}\left(\mathrm{~T} \leq 721^{\circ} \mathrm{C}\right.$ ) (see Table 4). The $\mathrm{x}$-ray diffraction data indicate that there is indeed a melt composition change due to the loss of $\mathrm{Cd}$ and $\mathrm{As}_{4}$ vapors as shown by the solidification of SiAs, CdSiAs ${ }_{2}$ and $\mathrm{Cd}_{3} \mathrm{As}_{2}$. The presence of small amounts of $\mathrm{CdAs}_{2}$ can be interpreted as condensation products from the $\mathrm{Cd}$ and $\mathrm{As}_{4}$ vapor phase above the melt. This condensate forms on the surface of the ingot and on the surface of the many pores distributed throughout the highly porous ingot.

The presence of free As in the ingot can be understood as also being a condensate. It was found in the presence of $\mathrm{CdAs}_{2}$ and $\mathrm{Cd}_{3} \mathrm{As}_{2}$ indicating that condensation sites are adjacent and that condensation occurs in sequence. The free As and $\mathrm{CdAs}_{2}$ co-condense from an arsenic rich vapor phase with frec As $\left(\mathrm{T}_{\mathrm{m}}=817^{\circ} \mathrm{C}, 28 \mathrm{~atm}\right)$ preceding $\mathrm{CdAs}_{2}\left(\mathrm{~T}_{\mathrm{m}}=621^{\circ} \mathrm{C}\right)$.

The solidification process of CdSiAs, melts occurs with simultancous evolution of $\mathrm{Cd}$ and $\mathrm{As}_{4}$ vapors from the hot melt in response to a condensation of these vapors on cold surfaces of the container, the external surface of the Ingot, and the ingot pore surfaces. Bestdes the relatively Indirect evfdence for this behavior found in the subsolidus compatability relationships, the obvious "constitutional" gradient found in some ingots as well as condensates on ampoule walls give further evidence of extensive vaporization and condensation.

The direct quench solidification of large ( $\left.>i_{g}\right)$ batches of CdSiAs $_{2}$ is especially difficult due to the turbulence mentioned above. Any further work in this area should be conducted with small batches $(<\because 2 \mathrm{~g})$ such that very little thermal gradient would be established during quenching. Smaller batch size would also have the additional benefit of increasing the quench rate. This would bring about a minimization of peritectic dissociation 
TABLE 4

Properties of Compositions In the Cd-S1-As Ternary System

\begin{tabular}{|c|c|c|c|c|c|}
\hline Composition & $\begin{array}{l}\text { Density } \\
\left(\mathrm{gm} / \mathrm{cm}^{3}\right)\end{array}$ & $\begin{array}{c}\text { Melting } \\
\text { Point } \\
\left({ }^{\circ} \mathrm{C}\right)\end{array}$ & $\begin{array}{l}\text { Melting } \\
\text { Behavior }\end{array}$ & $\begin{array}{l}\text { Vapor } \\
\text { Species }\end{array}$ & References \\
\hline $\mathrm{Cd}$ & 8.64 & 321 & Simple & Cd & 93,94 \\
\hline As & 5.73 & $\begin{array}{l}817 \\
(28 \text { atm })\end{array}$ & $\begin{array}{l}\text { Sublimes } \\
613^{\circ} \mathrm{C}\end{array}$ & $\mathrm{As}_{2} / \mathrm{As}_{4}$ & 93,94 \\
\hline Si & 2.33 & 1420 & Simple & $\mathrm{Si}_{2}$ & 93,94 \\
\hline $\mathrm{Cd}_{3} \mathrm{As}_{2}$ & 6.31 & 721 & Congruent & $\begin{array}{l}\mathrm{Cd} \\
\mathrm{As}_{2} / \mathrm{As}_{4}\end{array}$ & 94 \\
\hline $\mathrm{CdAs}_{2}$ & 5.88 & 621 & Congruent & & $91-93$ \\
\hline SiAs & 3.82 & 1083 & Congruent & $\mathrm{As}_{2} / \mathrm{As}_{4}$ & 92,94 \\
\hline $\operatorname{siAs}_{2}$ & -- & $944-1040$ & Incongruent & $\mathrm{As}_{2} / \mathrm{As}_{4}$ & 94 \\
\hline CdSiAs $_{2}$ & 5.12 & $821-943$ & $\begin{array}{l}\text { In congruent } \\
\text { Sub } 1 \text { imes } \\
620-800\end{array}$ & $\begin{array}{l}\mathrm{Cd} \\
\mathrm{As}_{2} / \mathrm{As}_{4}\end{array}$ & $\begin{array}{l}68,69 \\
84\end{array}$ \\
\hline
\end{tabular}


during the solidification of the ingot. A comparison of x-ray diffraction patterns such as those of Tables 1 and 2 shows that a qualitative decrease in ingot heterogeneity occurs with increasing quench rate (1.e., furnace quench being relatively slow, air quench being more rapld, and water quench being most rapid).

Smaller batch size would belng about a lower thermal gradient across the batch thereby minimizing batch heterogeneity in both the chemical and microstructural senses. The increased microstructural homogeneity in a small batch would have the advantage of optimizing the heat treatment homogenization of the batch. Small, uniform grains with high surface to volume ratio in the ingot would provide more surface free energy to drive the Interdiffusion of material as well as provide shorter paths to reaction sones،

\section{$\underline{2.2 \text { Sputtered F11ms }}$}

Experimental Techniques

The Initial objective was tu prepare stolchlomerric CdSiAs ${ }_{2}$ fllms from a macrohomogeneous target of $\mathrm{CdSIAs}_{2} \cdot$ Subsequent efforts used composite targets of $\mathrm{CdAs}_{2} / \mathrm{S} 1$, as described below.

The radio frequency sputtering system used to deposit Cd-S1-As thin flims consisted of a commercial sputtering module (R. D. Mathis Model SP 310) mounted on a vacuum system ut1lizing a turbomolecular pump (Welch, Model No. 3102). The sputtering parameters used are 11sted in Table 5.

The film thicknesses were determined by welghing the substrates on a microbalance before and after deposition, and assuming a composition of $\mathrm{CdS1As}_{2}$ of near theoretical density, $5.0 \mathrm{gm} / \mathrm{cm}^{3}$. These thicknesses were in good agreement $( \pm 5 \%)$ with those obtained by opt1cal interferometry.

The rate of material removal from the target was also monitored by determining the geometrical profile of the target surface with a sheet metal 
TABLE 5

Sputtering Parameters Used in the Deposition of CdSiAs 2 Thin Films

\begin{tabular}{lccccc}
\hline $\begin{array}{c}\text { Sputtering } \\
\text { Target }\end{array}$ & $\begin{array}{c}\text { rf } \\
\text { Power } \\
\text { (Watts) }\end{array}$ & $\begin{array}{c}\text { Argon } \\
\text { Pressure } \\
\text { (m Torr) }\end{array}$ & $\begin{array}{c}\text { Substrate } \\
\text { Heating } \\
\left({ }^{\circ} \mathrm{C}\right)\end{array}$ & $\begin{array}{c}\text { dc } \\
\text { Voltage } \\
(\mathrm{KV})\end{array}$ & $\begin{array}{c}\text { Duration } \\
\text { (Hr) }\end{array}$ \\
\hline CdSiAs $_{2}$ & $40-220$ & $5-32$ & RT to 535 & $1.5-4.0$ & $3.0-7.5$ \\
Bulls Eye (BE) & $80-190$ & $7-16$ & - & $0.7-1.8$ & $2.5-6.0$ \\
HEX A & $100-200$ & $9-32$ & - & $0.4-2.3$ & $1.5-3.5$ \\
HEX B & $100-200$ & $9-12$ & - & $2.0-3.0$ & $3.0-6.0$ \\
HEX C & $100-200$ & $7-15$ & - & $2.1-3.3$ & $3.5-4.0$ \\
Ta & $140-150$ & $7-13$ & - & $2.0-2.6$ & $2.5-3.5$ \\
Mo & 135 & 13 & - & 3.0 & 3.3 \\
\hline
\end{tabular}


micrometer.

\section{Target Fabrication}

The CdSiAs 2 was prepared by direct fusion of $\mathrm{CdSiAs}_{2}$ that had previously been synthesized by direct fusion from the pure elements. Crushed pieces of $\mathrm{CdSIAs}_{2}$ (containing small amounts of $\mathrm{CdAs}_{2}, \mathrm{Cd}_{3} \mathrm{As}_{2}$ and SiAs) were placed in a fused silica cylindrical container which contained a 3 " graphite disk on which the CdSiAs 2 rested. The container, $3 \frac{1 / 4}{4}$ in diameter and 2 " high, was evacuated and sealed. It was then heated and quenched by sitting it on an aluminum plate. "lhis target had an irregular shape approximately 2" in diameter and $\frac{1}{4} "$ thick. It was bonded to an aluminum backing plate with conducting epoxy.

A composite targer is illustrated in Figure 4. These were prepared by core drilling $23 / 64^{\prime \prime}$ holes In a $3 "$ diameter polycrystalline silicon plate and inserting 11/32" $\mathrm{CdAs}_{2}$ disks into those holes. The silicon and inserts were bonded to a $3 \frac{1}{4}$ " diameter copper backing plate, with thermosetting epoxy.

The CdAs ${ }_{2}$ Inserls were syilliestzed by welghting stolchiomertc quane1ties of pure cadmium. (5N) and arsenic (6N) into hollow graphite cylinders, which were in turn sealed into evacuated heavy-wall silica tubing. The graphite liners kept the final ingot from fracturing on cooling.

The resulting CdAs, ingots were found to be single phase and crystalline. by the electron microprobe and x-ray diffraction analysis. (Its relative ease of synthesis is assoclated with its eutectic melting and solidification behavior.) The ingots were sectloned Into disks on a diamond saw. They were ultrasonically cleaned in acetone and methanol.

Four composite targets were fabricated. The first was a silfcon disk with a single $\mathrm{CdAs}_{2}$ disk bonded at its center (Bulls Eye-BE). It was used to characterize the geometry of sputtering from a single insert as a test 


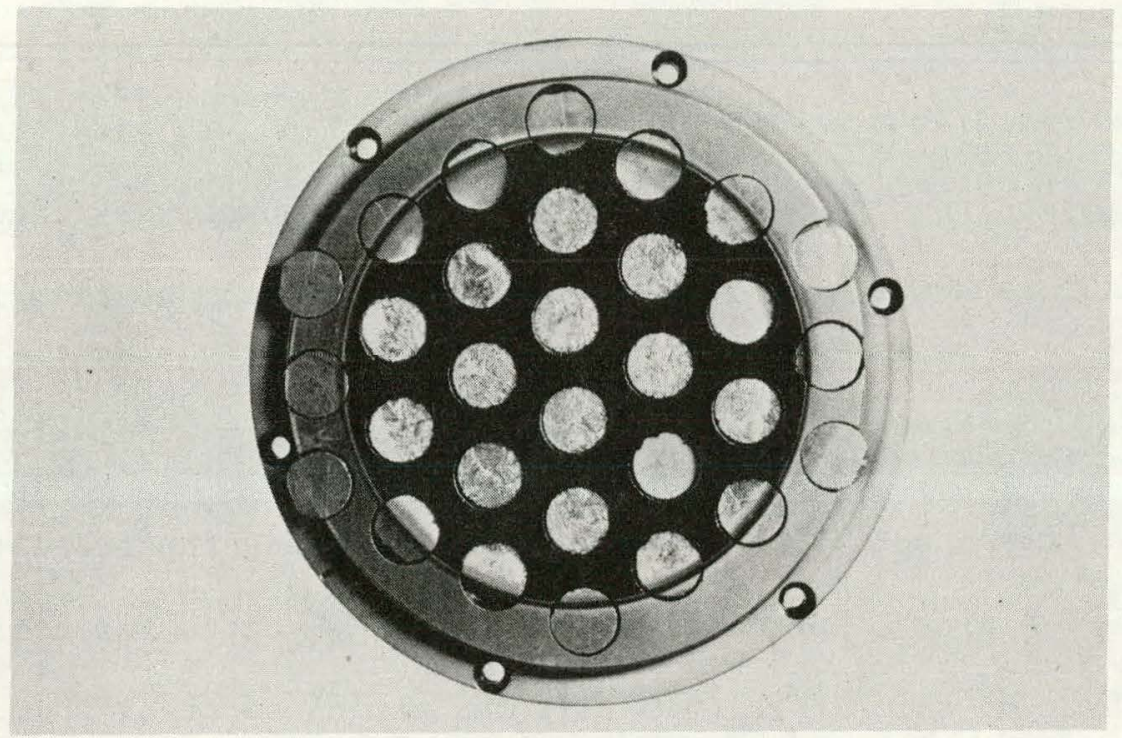

Figure 4. Photograph of Composite Sputter Target HEX A 
of possible imaging effects between the two-phase target and the substrate plane.

The other three composite targets (HEX A, HEX B, and HEX C) consisted of a Si plate with $\mathrm{CdAs}_{2}$ disks inserted in a hexagonal array. The number and spacing of the inserts were chosen to yield Si/CdAs ${ }_{2}$ area ratios of $1.00,1.47$ and 2.27 (HEX A, HEX B and HEX C).

Heat Treatment

Sputtered films were subjected to various heat treatments. The most frequently employed method was heat treatment in evacuated vycor ampoules having approximate1y 0.1 gram of $\mathrm{CdAs}_{2}$ included along with the film. The $\mathrm{CdAs}_{2}$ provided an overpressure of $\mathrm{Cd} \mathrm{As}_{4}$ and $\mathrm{As}_{2}$ in order to avoid losses of $\mathrm{Cd}$ and As from the film and to attain stoichometry by incorporation of Cd or As into the films. Other methods used were: heating in sealed, evacuated vycor ampoules without $\mathrm{CdAs}_{2}$; heating in sealed evacuated vycor ampoule with $\mathrm{Cd}$; and heating in air.

The films heat treated were on the following substrates: fused silica, Corning 7059 glass, Mo-coated fused silica, Ta-coated fused silica, Ta-coated 7059 glass, Mo shim stock $\left(0.002^{\prime \prime}\right)$, and stainless steel shim stock $(0.001 "$ and $\left.0.002^{\prime \prime}\right)$.

Resu1ts and Discussion

F'ilms From Ternary Target

The films formed by sputtering from the polycrystalline $\mathrm{CdSiAs}_{2}$ target were cadmium deficient and amorphous. Attempts to induce crystallinity by heating the substrates were not successfu1. The effect of substrate heating on film composition as determined by electron microprobe is seen in Flgure 5. The first substrate temperature shown is that obtained without applying power to the substrate heater. When the substrate heater was heated to only $270^{\circ} \mathrm{C}$, the cadmium content had dropped to less than $2 \%$, and became even 


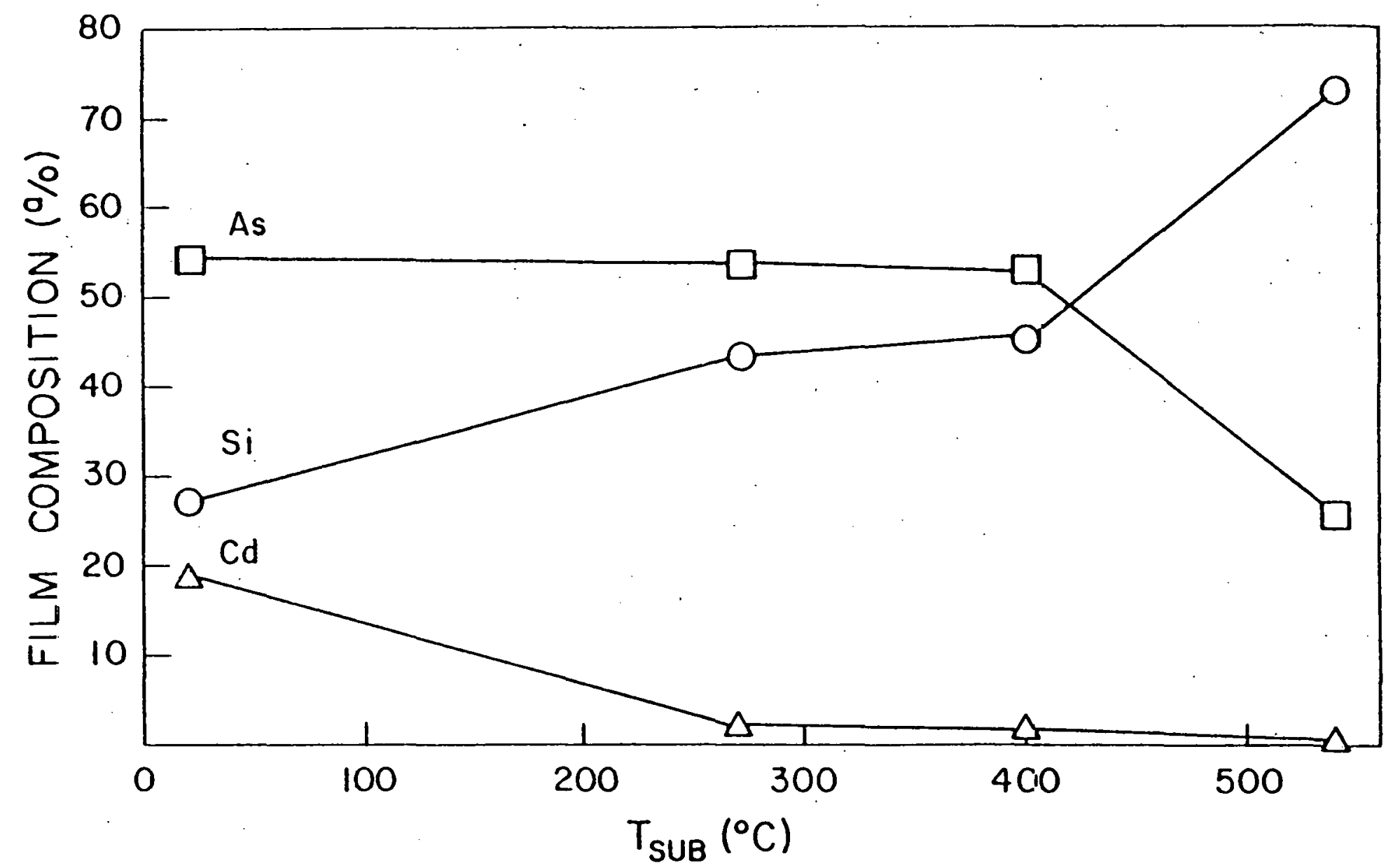

Figure 5. Effect of Substrate Temperature on Sputtered Film Composition Determined by Electron Microprobe Analysis: Films Deposited Using CdSiAs 2 Target 
lower as higher substrate temperatures were used. At very high heater temperatures (above $400^{\circ} \mathrm{C}$ ), the As content also dropped from $53 \%$ to $30 \%$.

The cadmium content was also found to be a function of the previous service of the polycrystalline CdSiAs 2 target. It was found that the Cd content dropped from $21 \%$ to $10 \%$ over three 200 watt runs. It was evident that the target surface was becoming Cd deficient with continued use and this depletion was hastened, if not caused; by chamber heating during runs in which the substrate heater was turned on.

\section{Composite Targets}

Sputtering from the first composite target (BE), consisting of a single $\mathrm{CdAs}_{2}$ disk at the center of a silicon plate, established that atom transport was diffusion controlled from target to substrate. The Cd and As atoms were evenly distributed over the entire substrate holder area, even though they originated from a small spot. This was shown by the microprobe elemental analyses of $\mathrm{Cd}$, As and $\mathrm{S} 1$ as a function of substrate location. This experiment confirmed that there would be no imaging effects between the two-phase targets and the substrates.

For the hexagonal composite targets, film composition was controlled by varying the $\mathrm{Si} / \mathrm{CdAs}_{2}$ area ratio of the target, by heat treatment, and by varying the power level used during sputtering.

The effect of the target Si/CdAs, area ratio on film composition is shown in Table 6.

Deposic1on rates: I'he deposition rates of amorphous Cd-S1-As films at the center of the substrate plane are shown in Table 7. The Si results for the bulls eye target indicate that the sputtered material condenses on an area 9 to 10 times larger than the target. The planar area of the substrate stage is approximately 50 square inches or 8.4 times the exposed area of 
TABLE 6

Film Compcisition Determined by Electron Microprobe Analysis for Films Deposited on Stbstrates Located At the Center of the Substrate Stage: rf Power Fixed at 100 Watts; Comparison of Different Targets

\begin{tabular}{|c|c|c|c|c|c|c|c|}
\hline \multirow{2}{*}{$\begin{array}{c}\text { Target } \\
\text { Ta }\end{array}$} & \multirow[b]{2}{*}{$\begin{array}{c}\text { Si/CdAs2 } \\
\text { Ratio }\end{array}$} & \multicolumn{3}{|c|}{ Composition (\%) } & \multicolumn{3}{|c|}{ Elemental Ratios } \\
\hline & & Cd & Si & As & As / Si & $\mathrm{Cd} / \mathrm{Si}$ & $\mathrm{As} / \mathrm{Cd}$ \\
\hline \multicolumn{2}{|c|}{$\begin{array}{l}\text { Stoichiometric } \\
\text { CdSiAs }\end{array}$} & 25.0 & 25.0 & 50.0 & 2.00 & 1.00 & 2.00 \\
\hline HEX A & 1.00 & 25.4 & 14.8 & 59.9 & 4.05 & 1.72 & 2.35 \\
\hline HEX B & 1.47 & 25.7 & 17.6 & 56.7 & 3.22 & 1.46 & 2.21 \\
\hline HEX C & 2.27 & 17.2 & 28.7 & 54.1 & 1.89 & D. 60 & 3.15 \\
\hline $\begin{array}{l}\text { HEX C } \\
\text { (Heat Treat at } \\
600^{\circ} \mathrm{C} \text { in } \mathrm{Cd}, \mathrm{As}_{4} \\
\text { ambient) }\end{array}$ & 2.27 & 24.2 & 26.3 & 49.5 & 1.88 & 0.92 & 2.04 \\
\hline
\end{tabular}


TABLE 7

Deposition Rates For Films Deposited From the Composite Targets at the Center of the Substrate Stage

\begin{tabular}{|c|c|c|c|c|c|c|c|}
\hline \multirow{2}{*}{\multicolumn{2}{|c|}{ Target/Run }} & \multirow[b]{2}{*}{ Substrate } & \multirow[b]{2}{*}{$\begin{array}{c}\text { Power } \\
\text { (Watts) }\end{array}$} & \multirow[b]{2}{*}{$\begin{array}{l}d c V \\
(K V)\end{array}$} & \multicolumn{2}{|c|}{ Rates } & \multirow[b]{2}{*}{$\frac{\text { Sputter Rate }}{\text { Deposition Rate }}$} \\
\hline & & & & & $\begin{array}{l}\text { Th1 ckness } \\
(\hat{A} / \mathrm{m})\end{array}$ & $\begin{array}{c}\text { Mass } \\
\left(\mu \mathrm{g} / \mathrm{cm}^{2}-m\right)\end{array}$ & \\
\hline $\mathrm{BE}$ & $\begin{array}{l}1 \\
2 \\
3 \\
4 \\
5 \\
6 \\
7\end{array}$ & $\begin{array}{l}7059 \\
7059 \\
7059 \\
7059 \\
7059 \\
7059 \\
7059\end{array}$ & $\begin{array}{r}80 \\
190 \\
100 \\
95 \\
80 \\
80 \\
100\end{array}$ & $\begin{array}{l}1.8 \\
1.0 \\
1.2 \\
1.2 \\
0.7 \\
0.9 \\
1.3\end{array}$ & $\begin{array}{r}128 \\
139 \\
84 \\
82 \\
118 \\
149 \\
195\end{array}$ & $\begin{array}{l}3.0 \\
3.3 \\
1.9 \\
1.9 \\
2.8 \\
3.5 \\
4.6\end{array}$ & $\begin{array}{r}9.9 \\
8.7 \\
8.6 \\
14.6 \\
2.3 \\
4.2\end{array}$ \\
\hline HEX A & $\begin{array}{l}1 \\
2 \\
3 \\
4 \\
5 \\
6 \\
7 \\
8\end{array}$ & $\begin{array}{l}7059 \\
7059 \\
7059 \\
7059 \\
7059 \\
7059 \\
7059 \\
7059\end{array}$ & $\begin{array}{l}200 \\
100 \\
100 \\
150 \\
130 \\
100 \\
180 \\
160\end{array}$ & $\begin{array}{l}1.6 \\
0.5 \\
0.4 \\
0.7 \\
0.8 \\
0.7 \\
2.3 \\
1.8\end{array}$ & $\begin{array}{r}91 \\
224 \\
188 \\
186 \\
215 \\
228 \\
160 \\
240\end{array}$ & $\begin{array}{r}4.5 \\
11.2 \\
9.4 \\
9.3 \\
10.8 \\
11.4 \\
8.0 \\
12.0\end{array}$ & $\begin{array}{r}-- \\
20.9 \\
13.1 \\
18.2 \\
22.0 \\
16.8 \\
166.6 \\
74.2\end{array}$ \\
\hline HEX B & $\begin{array}{l}1 \\
2 \\
3 \\
4 \\
5\end{array}$ & $\begin{array}{l}7059 \\
7059 \\
7059 \\
\text { Mo } \\
\text { Mo }\end{array}$ & $\begin{array}{l}100 \\
150 \\
200 \\
150 \\
100\end{array}$ & $\begin{array}{l}2.2 \\
2.5 \\
2.9 \\
2.5 \\
2.2\end{array}$ & $\begin{array}{r}244 \\
239 \\
199 \\
66 \\
46\end{array}$ & $\begin{array}{r}12.2 \\
11.9 \\
10.0 \\
3.3 \\
2.3\end{array}$ & $\begin{array}{c}15.7 \\
24.9 \\
36.8 \\
=- \\
=-\end{array}$ \\
\hline HEX $\mathrm{C}$ & $\begin{array}{r}1 \\
2 \\
3 \\
4 \\
5 \\
6 \\
7 \\
8 \\
9 \\
10 \\
11 \\
13 \\
13\end{array}$ & $\begin{array}{l}7059 \\
7059 \\
7059 \\
\mathrm{Mo} \\
7059 \\
\mathrm{Mo} \\
\mathrm{SS} \\
\mathrm{Mo} \\
\mathrm{S1O} \\
\mathrm{Mo} / \mathrm{S1O}_{2} \\
\mathrm{Ta} / \mathrm{S1O}_{2} \\
\mathrm{70S9} \\
\mathrm{Ta} / 7059\end{array}$ & $\begin{array}{r}110 \\
150 \\
200 \\
200 \\
100 \\
150 \\
125 \\
90 \\
90 \\
100 \\
90 \\
90 \\
100\end{array}$ & $\begin{array}{l}2.1 \\
2.7 \\
2.9 \\
2.8 \\
2.1 \\
2.4 \\
2.2 \\
1.9 \\
2.1 \\
2.0 \\
1.9 \\
1.9 \\
3.0\end{array}$ & $\begin{array}{r}167 \\
117 \\
224 \\
112 \\
147 \\
43 \\
56 \\
39 \\
156 \\
119 \\
112 \\
153 \\
104\end{array}$ & $\begin{array}{l}8.4 \\
5.8 \\
9.0 \\
4.5 \\
7.4 \\
2.2 \\
2.8 \\
1.9 \\
7.8 \\
6.0 \\
5.6 \\
7.7 \\
5.3\end{array}$ & $\begin{array}{r}30.8 \\
44.2 \\
32.9 \\
59.7 \\
35.3 \\
143.2 \\
85.8 \\
143.3 \\
28.8 \\
78.5 \\
36.2 \\
26.3 \\
40.7\end{array}$ \\
\hline
\end{tabular}


the target. A certain smaller amount of material also deposited on the wall of the chamber. Therefore, relatively little resputtering of SI occurred as compared to $\mathrm{Cd}$ and As. In the case of target HEX A, the sputtering rates were from 13 to 167 times larger than the deposition rates. The great range indicates the sensitivity of Cd net deposition rate (and As to a lesser degree) to the sputter conditions. The larger discrepancies between $\mathrm{CdAs}_{2}$ sputter rates and film deposition rates are most likely due to resputtering/backscattering phenomena. The last two runs of HEX A with relatively high dc voltages had large differences in sputtering and deposition indicating that dc voltage/rf power influenced both sputtering and resputtering rates.

This finding is consistent with all of the hexagonal targets for films on glass substrates. Fllms on metal sh1m stock and metal coated glass experfence conslderably more resputtering except for the case of Ta coated glass. In that instance the resputtering increase was slight. The increased resputtering losses of $\mathrm{Cd}$ and As could be seen more clearly in the 11ght of poor metal-substrate contact. The poor contact was responsible for increased substrate heating that enhanced resputtering.

The ratios of sputtering rates to deposition rates for the $\mathrm{BE}$ target did not respond to changes in dc voltage. Th1s is understandable in the light of the resigtance of $S 1$ to sublimation/resputtering. They did respond, however, to the decrease from 3 to 2 inches in target-substrate separation. The effective deposition area was decreased by a factor of approximately 2 ylelding films of twice the thickness. This effect is anticipated from a consideration of the syatem geometry.

It can also be seen that higher dc voltages were generally malntained 
on targets HEX B and HEX C than on targets HEX A and BE. A corresponding increase in sputter yields resulted.

Film composition: The composition of deposited films did not closely resemble the material ratios sputtered from the targets, as already mentioned in the case of Cd deficlent films deposited from target HEX $C$. The rf power levels used and the assoclated localized plasma heating of substrates were seen to Influence the resulting film composition. As an example, the effect of rf power on film composition is shown in Figure 6 for target HEX A.

The dependence of film composition on substrate location 1s 11lustrated in Figure 7, for target HEX C. The other targets ylelded similar results. The cadmium content was consistently less in the center of the substrate holder, and this effect was more pronounced at the higher power levels. The $S 1$ content nearly mirrors the $C d$ content. The Cd contents of the films varled about $1 \%$ over a central two centimeters where power levels of 100 and 150 watts were used. At 200 watts, the variation was $9.5 \%$.

These Cd deficlencles at the center of the stage are assoclated with elevated temperatures at the film surface: Substrate temperature (as measured by a thin film sensor) versus sputterling power 1s shown in Higure 8. A center temperature of $480^{\circ} \mathrm{C}$ was measured when the power level was 200 watts, $410^{\circ} \mathrm{C}$ when the power level was $150 \mathrm{w}$, and only $270^{\circ} \mathrm{C}$ when 1t was $100 \mathrm{w}$. In the latter case, the temperature was $270^{\circ} \mathrm{C}$ at $2 \mathrm{~cm}$ from the center, and $150^{\circ} \mathrm{C}$ at $4 \mathrm{~cm}$. These strong temperature prof 11 es are due to the greater plasma densities near the center; and they cause more pronounced cd resputtering there. The substrate temperature follows a $T^{4}$ relationship with rf power as was seen by other investigators ${ }^{(5)}$. Compositions for several runs of films sputtered onto glass and metal 


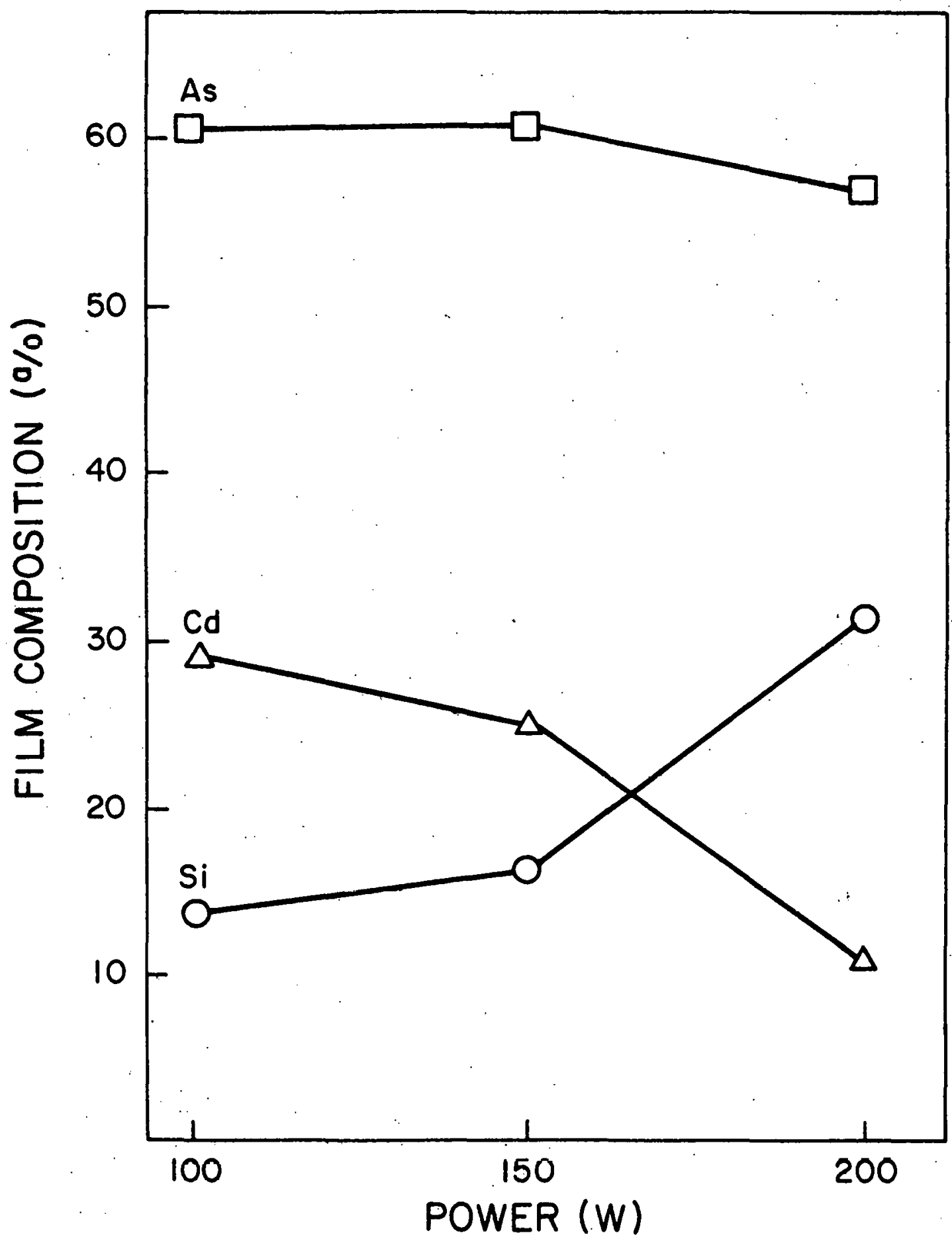

Figure 6. Effect of rf Power on Film Composition, Target HEX A 


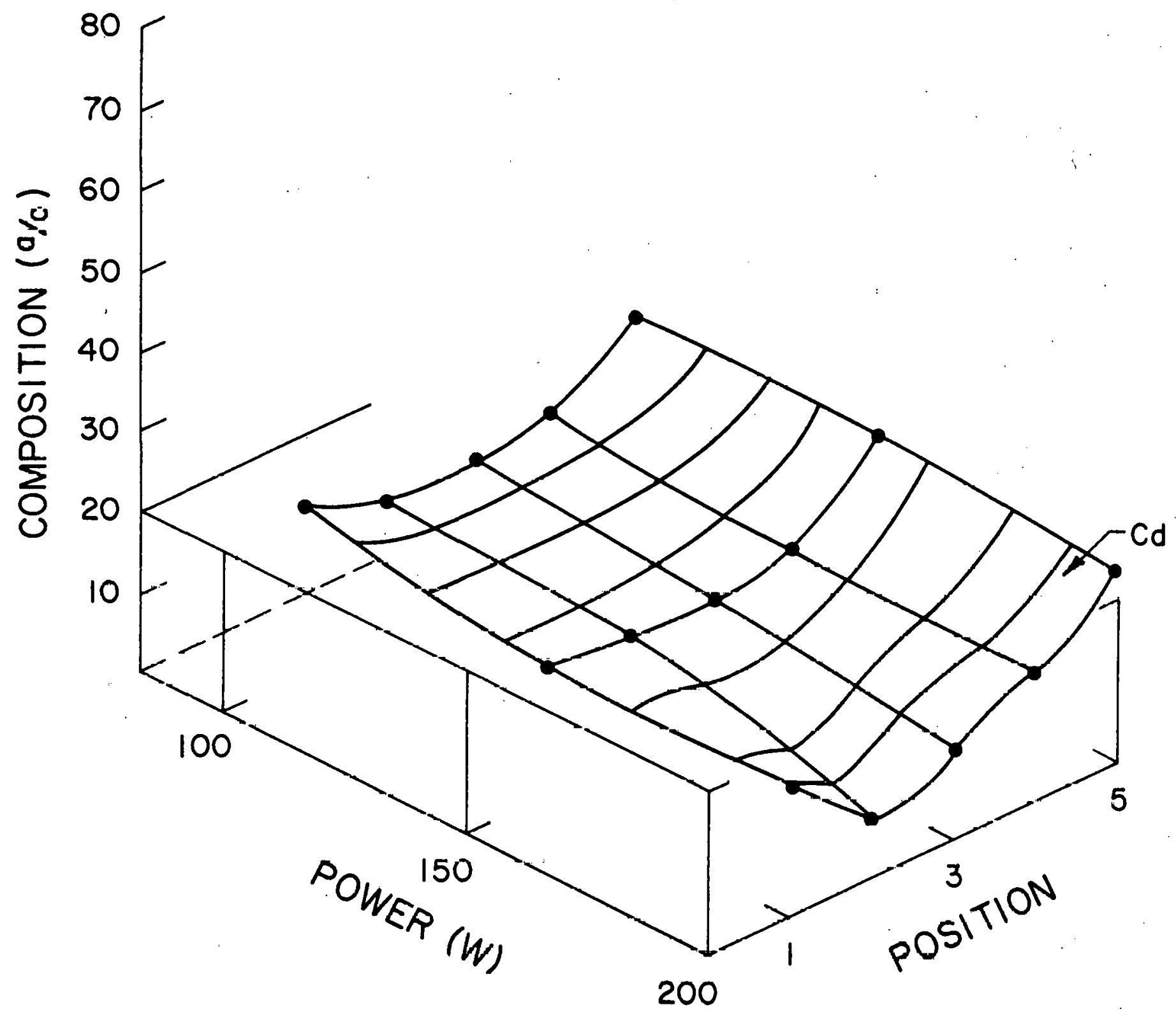

Figure 7: Effect of Power and Position in Cd Content in Sputtered Thin Films of CdSiAs, Target HEX C 


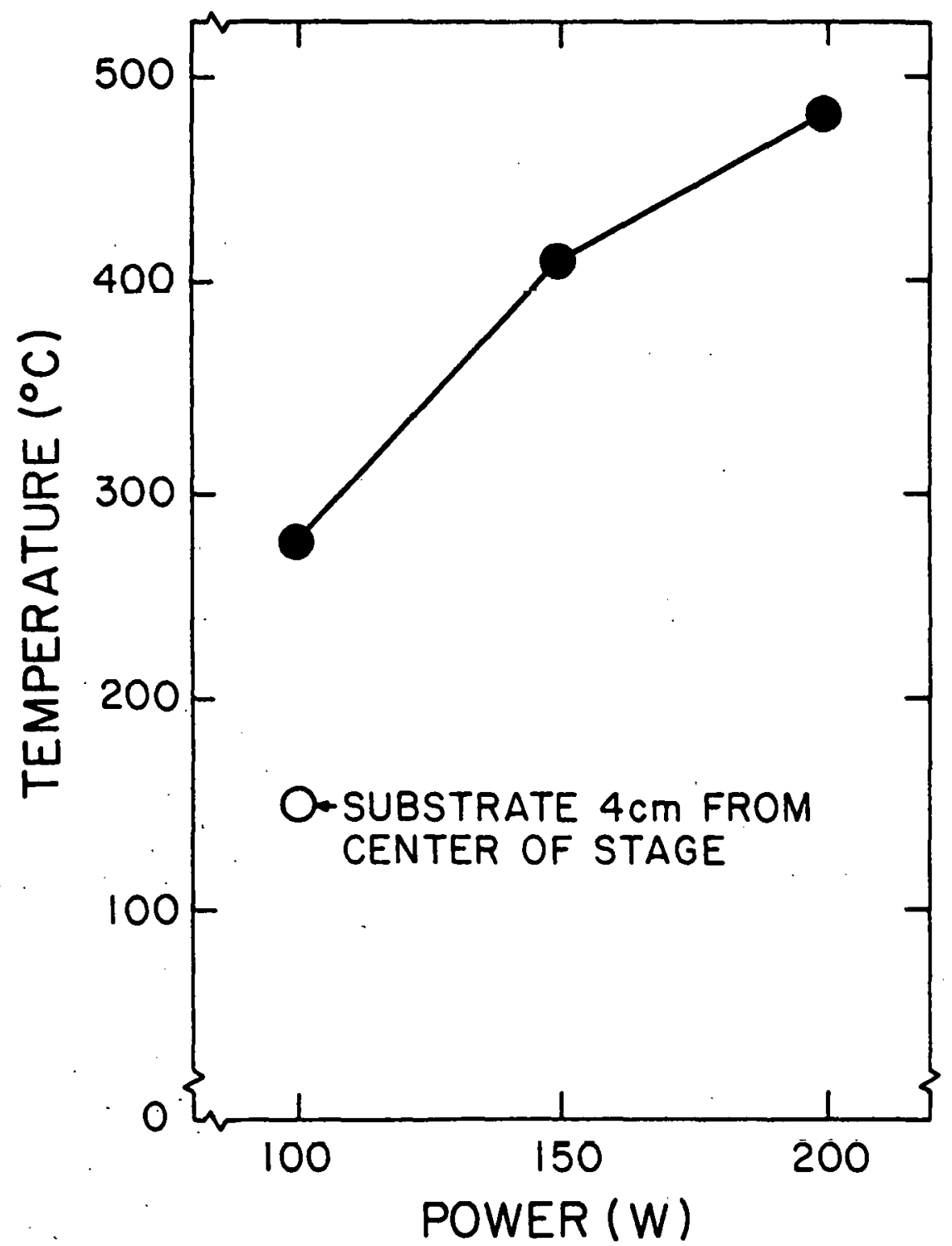

Figure 8. Effect of rf Power on Substrate Temperature, Target HEX C 
coated glass are shown in Table 8. The range of values for each coponent along with average value \pm standard deviation are listed along with ratios As/Si, $\mathrm{Cd} / \mathrm{Si}$ and As/Cd for each run. The general range of compositions was similar in each case, since the sputtering conditions were very similar with power levels of 90 to 100 watts.

On the average, the $C d$ content of the amorphous films was 3 to $3.5 \%$ below the "stoichiometric" value of $25 \%$ in all but the Ta coated glass specimens. Films on the Ta coated substrates had average Cd content at or ilear $(-1.6 \%)$ the "otolchiometric" value. This effert when coupled with lower As content on Ta coated glass gave As/Cd rac1os of 2.09 and $1.89-$ much lower than for films on other substrates.

The average $\mathrm{S} 1$ content was $27.2,27.2$ and $27.8 \%$ or 2.2 to $2.8 \%$ above the "stoichiometric" value in the case of films on metal coated glass substrates (either Mo or Ta). Films formed directly on glass had higher Si contents of 28.5 and $29.6 \%$.

The average As values were elther very close to the "stolchlometric" value of $50 \%$ or within $2 \%$ of it (1.e., a $4 \%$ deviation). The \% deviation of As from the "stoichiometric" value $(-4 \%)$ was much less than the deviation for either Cd, having a deviation of $-14 \%$, or Si which had a deviation of $+12 \%$. This indicated that variations in the film content were due in large measure to variations in $\mathrm{Cd}$ and $\mathrm{S} 1$ content.

\section{Heat Treatment}

\section{Of Films on Glass}

Thin film a-CdSiAs 2 on glass was transformed from amorphous to crystalline $\mathrm{CdS} \mathrm{As}_{2}$ by heat treatment at $550^{\circ} \mathrm{C}$ to $615^{\circ} \mathrm{C}$. Lower temperature did not provide enough thermal energy to effect the crystallization, and 
table 8

Low rf Power Sputter Deposition of Thin F1/ms From Target HEX C Onto Glass and Metal Coated Gless Substrates-Electron Microprobe Analysis of F1lm Composition

\begin{tabular}{|c|c|c|c|c|c|c|c|c|c|c|c|}
\hline \multirow[b]{2}{*}{ Run } & \multirow{2}{*}{$\begin{array}{l}\text { Power } \\
\text { iWates) }\end{array}$} & \multirow[b]{2}{*}{ Substrate } & \multicolumn{3}{|c|}{ EMPA Funge ( $(x)$} & \multicolumn{3}{|c|}{$\begin{array}{c}\text { EMPA Average (z) } \\
\pm S\end{array}$} & \multicolumn{3}{|c|}{ Ratius } \\
\hline & & & cd & si & As & Cd & s1 & As & $\mathbf{A s} / \mathbf{S} \mathbf{1}$ & Cd/S1 & As / Cd \\
\hline 9 & 90 & $310_{2}$ Class & $15.5-28.0$ & $24.3-31.4$ & $46.9-53.4$ & $21.5 \pm 3.3$ & $28.5 \pm 1.8$ & $50.0 \pm 1.8$ & 1.75 & 0.75 & 2.33 \\
\hline 10 & 100 & $\mathrm{Mo}_{1} \mathrm{~S} \mathrm{O}_{2}$ & $17.2-25.4$ & $24.5-.29 .4$ & $48.9-54.3$ & $.21 .5 \pm 2.4$ & $27.2 \pm 1.5$ & $51.3 \pm 1.6$ & 1.89 & 0.79 & 2.39 \\
\hline 11 & 90 & $\mathrm{Ta} / \mathrm{SiO}_{2}$ & $18.3-27.7$ & $25.8-31.5$ & $46.0-50.8$ & $23.4 \pm 3.0$ & $27.8 \pm 1.7$ & $48.8 \pm 1.5$ & 1.75 & 0.84 & 2.09 \\
\hline 12 & 90 & 7059 & $18.2-26.3$ & $26.2-32.1$ & $46.6-50.0$ & $21.9 \pm 2.4$ & $29.6 \pm 1.9$ & $48.4 \pm 1.1$ & 1.64 & 0.74 & 2.21 \\
\hline 13 & 100 & $\mathrm{Ta} / 7059$ & $20 . j-28.7$ & $25.3-29.7$ & $45.4-50.3$ & $25.2 \pm 2.6$ & $27.2 \pm 1.2$ & $47.6 \pm 1.6$ & 1.75 & 0.93 & 1.89 \\
\hline 14 & 100 & Ta & $23 . i-27.2$ & $26.3-29.2$ & $46.1-48.6$ & $24.9 \pm 1.2$ & $28.0 \pm 0.9$ & $47.1 \pm 0.7$ & 1.68 & 0.89 & 1.89 \\
\hline
\end{tabular}


higher temperature caused diffusion of film and substrate leaving the glass substrate tinted in appearance. As. little as 3 hours effected the change.

The resulting crystal structure was the chalcopyrite structure of $\mathrm{CdSIAs}_{2}$. The crystals were extremely small as evidenced by broad peaks on the $x$-ray diffraction patterns and by low peak heights. Increasing the heat treatment duration from one day to one week was found to alter the film structure. The $x$-ray patterns of the longer heat treated films had narrower peaks, Increased peak helghts, and Increased crystal texture as seen by the presence of more CdSIAs 2 peaks (Table 9).

The increased heat treatment time of one week brought about the noticeable effect of diffusion/reaction as evidenced by the presence of a non-CdS1As 2 x-ray peak corresponding to $\mathrm{As}_{2} \mathrm{O}_{3}$ at $32.2^{\circ} 2 \theta$.

The type of glass substrate was found to be of little slgnificance in obtaining crystalline CdSiAs ${ }_{2}$ films. The large thermal expansion mismatch of $\mathrm{CdSIAs}_{2}$ fllms and fused $\mathrm{SIO}_{2}$ resulted $\mathrm{in}$ film cracking and in a few cases of peel off. F1lms on Curulug 7059 glass ecndod to be pitter. They may have been due to insufficlent cleaning and/or to thermal expansion mlomateh. Of Films on Metal Coated Glass

Molybdenum coated silica was found to be an unsatisfactory substrate material due to loss of adhesion of Mo during heat treatment.

Tantalum coated sllica served well as a conductlve substrate materlal In that the Glass-Metal and Metal-CdS1As 2 bond strengths were sufficlent to maintain a good degree of mechanical integrity in spite of high thermal expansion stresses. Cracks were observed extending from the glass-metal 1nterface through the $\mathrm{Ta}$ into the $\mathrm{CdS1As}_{2}$. Th18 is seen in F1gure 9. No cracks were observed in the $\mathrm{Ta}$ that had not been covered by $\mathrm{CdSIAs}_{2}$. No appreclable loss of f1lm occurred as a result of the cracking. Th1s 
TABLE 9

X-Ray Diffraction Pattem of Heat Treated Films on Glass: One Day Duration Compared to One Week Duration

\begin{tabular}{|c|c|c|c|c|c|c|}
\hline \multicolumn{3}{|c|}{1 Day } & \multicolumn{3}{|c|}{1 Week } & \multirow[b]{2}{*}{$h_{k}$ l } \\
\hline$d(\AA)$ & ${ }^{\circ} 2 \theta$ & $I / I_{0}$ & $d(\AA)$ & ${ }^{\circ} 2 \theta$ & $I / I_{0}$ & \\
\hline 5.185 & 17.1 & 2 & 5.185 & 17.1 & 7 & 101 \\
\hline \multirow[t]{3}{*}{3.314} & 26.9 & $\begin{array}{l}100 \\
(250 \mathrm{cps})\end{array}$ & 3. 314 & 26.9 & $\begin{array}{l}100 \\
(700 \mathrm{cps})\end{array}$ & 112 \\
\hline & & & 3.084 & 28.95 & 10 & 103 \\
\hline & & & 2.780 & 32.2 & & $\mathrm{As}_{2} \mathrm{O}_{3}$ \\
\hline \multirow[t]{2}{*}{2.557} & 35.1 & 10 & 2.557 & 35.1 & 15 & 211 \\
\hline & & & 2.132 & 42.4 & 5 & 213 \\
\hline \multirow[t]{2}{*}{2.080} & 43.5 & 15 & 2.083 & 43.45 & 20 & 220 \\
\hline & & & 2.036 & 44.5 & 3 & 105 \\
\hline \multirow[t]{4}{*}{2.000} & 45.45 & 25 & 1.998 & 45.4 & 30 & 204 \\
\hline & & & 1.9 .45 & 46.7 & 2 & 222 \\
\hline & & & 1.929 & 47.1 & 5 & 301 \\
\hline & & & 1.870 & 48.7 & 5 & \\
\hline \multirow[t]{2}{*}{1.762} & 51.9 & 5 & 1.762 & 51.9 & 20 & 312 \\
\hline & & & 1.658 & 55.4 & 10 & 116 \\
\hline
\end{tabular}




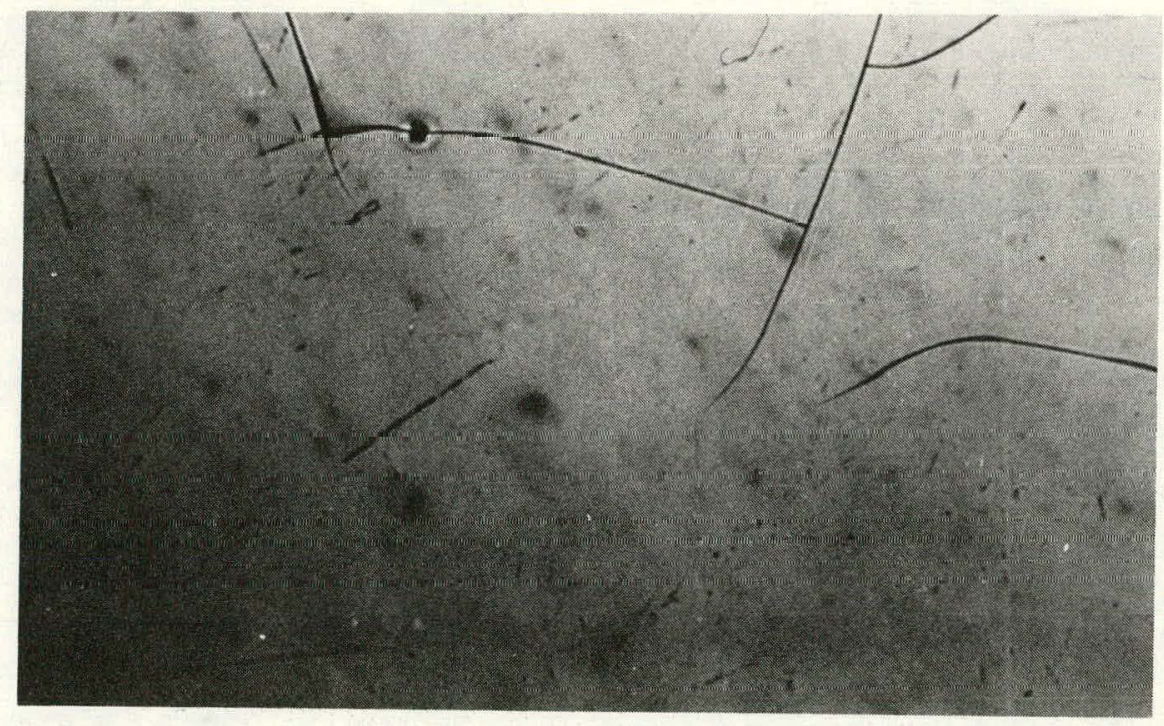

Figure 9. Photomicrograph of $\mathrm{CdSiAs}_{2} / \mathrm{Ia} / \mathrm{SiO} \mathrm{O}_{2}$ Thin Film un Glass Layer Structure Showing Cracks Initiating at $\mathrm{Ta} / \mathrm{SiO}_{2}$ Interface $(260 \mathrm{x})$ 
indicated that cracking relieved the residual thermal stresses while high Interfacial bond strengths maintalned the CdSIAs ${ }_{2}-\mathrm{Ta}-\mathrm{Glass}$ layers intact. Extended heat treatment for periods of one week or more did not produce the same effect in films on Ta coated glass as in their counterparts on glass alone. The crystallites did not increase in texture or grain size. Totally unrelated XRD peaks were observed. The new peaks were found to be Ta peaks, indicating that diffusion of $\mathrm{Ta}$ into the $\mathrm{CdSIAs}_{2}$ or loss of CdS1As ${ }_{2}$ into aiillent had taken place. The introduction of Ta into the CdSiAs ${ }_{2}$ lattlce would have a deleterious effect on attainment of CdSiAs ${ }_{2}$ cyrstal perfection. It is this factor that causes the difference between CdSiAs ${ }_{2}$ on Ta coated glass (poorly crystalline) and $\mathrm{CdSiAs}_{2}$ on glass (improved crystallinity) when both were heat treated for one week.

\section{Of Films on Metal}

Heat treated films on steel and moly shim stock exhibited diffusion/ chemical reaction effects at temperature lower than the crystallization temperature $\left(-500^{\circ} \mathrm{C}\right)$. This showed the unsuitability of these substrates for CdSiAs 2 films where post deposition heat treatments above $500^{\circ} \mathrm{C}$ are necessary:

Effect on Film Composition and Structure

The results of microprobe analysis of heat treated films are plotted in Figure 10. In this figure, Cd content ranges from $18 \%$ to $26 \%$. The Si content ranged from $26.5 \%$ to $31.5 \%$ while the As content ranged from $47: 5 \%$ to $50.3 \%$.

The effect of heat treatment seen in Figure 10 was to narrow the compositional differences between the films and to generate films deficient in both $\mathrm{Cd}$ and As. For example, the Cd content of heat treated films ranged from $22 \%$ to $24 \%$, the Si content ranged from $29 \%$ to $31 \%$, and the As content ranged from $46.8 \%$ to $48.5 \%$. The average $\mathrm{Cd}$ and As defictenctes were found 


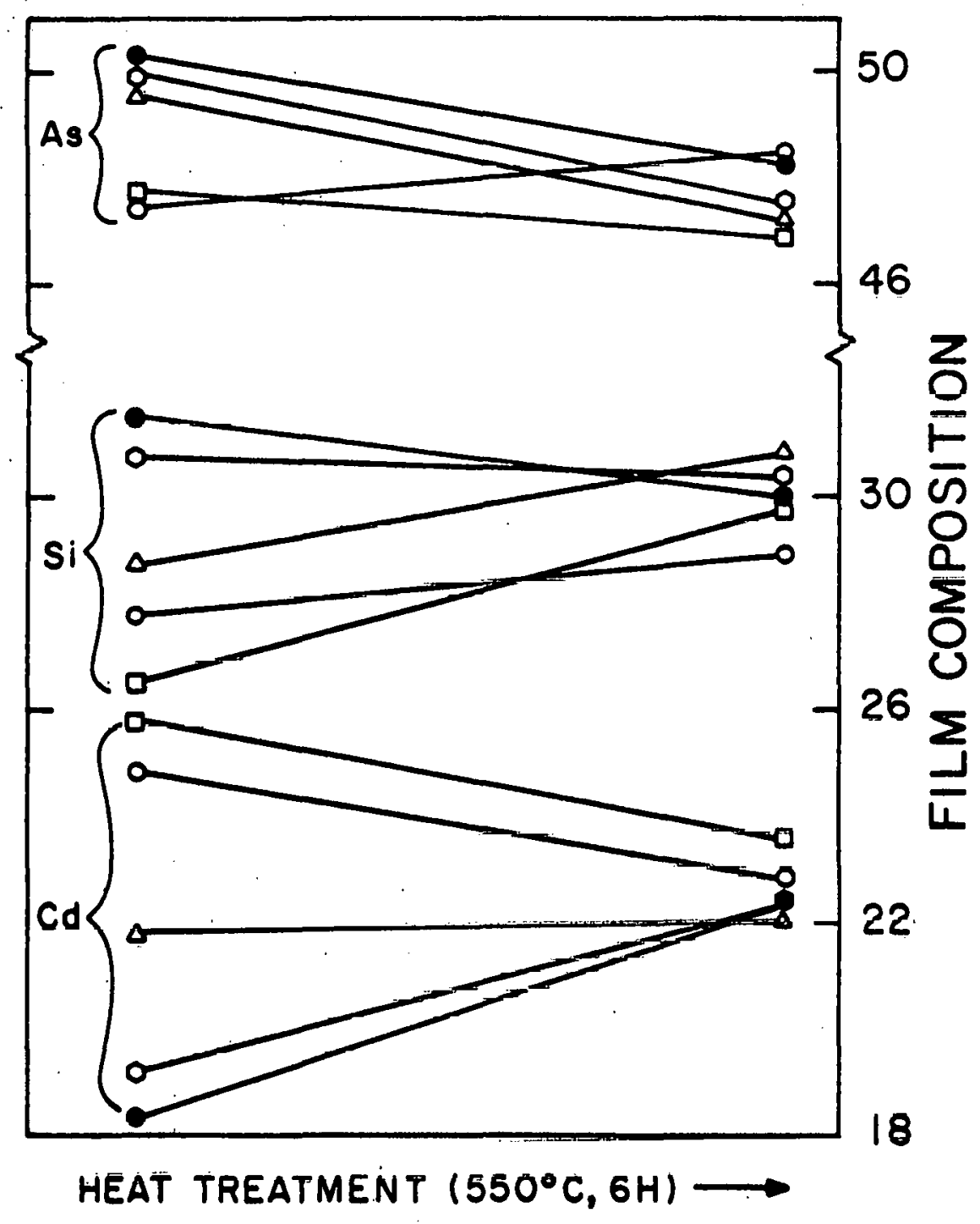

Figure 10. Compositional Changes Occurring in Heat Treated Films, HEX $C--11$ 
to be $2.3 \%$ and $2.5 \%$ respectively.

Properties of Films

The quality of films was not especlally conducive to property measurements (primarily due to cracking) except in a few cases. It was found that films underwent a great change in thelr optical and electrical behavior due to crystallization.

Indium was found to form an ohmic contact to heat treated films, as evidenced by I-V 1inearity. Typical values for a heat treated film (No. 17 , $615^{\circ} \mathrm{C}, 17$ hours) are as follows: sheet resistance $12 \Omega / \square$, reslstivity

$2.1 \Omega \mathrm{cm}$ (across a range of $\pm 10 \mathrm{v}$ ).

The resistivity of amorphous $\mathrm{CdSIAs}_{2}$ films was generally too high to measure with methods employed in the laboratory. The resistivity would therefore be greater than $10^{8} \mathrm{ohm}-\mathrm{cm}$. Comparison of the crystallized and amorphous films shows a greater than $10^{7}$ decrease in resistivity due to crystallization. Reslstivities of single crystal CdSIAs, reported in the 11terature range from 0.3 to $5.0 \mathrm{ohm}-\mathrm{cm}$, which $1 \mathrm{~s}$ very close to the resistivity measured for our heat treated f11ms.

In like manner, optical propertles of films also changed markedly with heat treatment. Amorphous films has absorption edge at about $1.39 \mathrm{eV}$, simflar to the band gap of $1.4 \mathrm{eV}$ reported for bulk a-CdSiAs ${ }_{2}(6,7)$. On one of the better (1.e. less cracks) samples, the absorption coefficient at $0.6 \mu \mathrm{m}$ was measured to be $2 \times 10^{4} \mathrm{~cm}^{-1}$, with an optical cutoff at $1.55 \mathrm{eV}$. D1scussion of Heat Treatment of a-CdS1As2 Thin F11ms

Crystallization

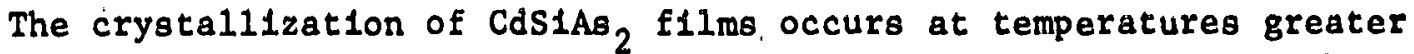
than about $500^{\circ} \mathrm{C}$. This compares with the crystallization of bulk a-CdS1 ${ }_{2}$ 
at temperatures of $480^{\circ} \mathrm{C}^{(4)}$ and $520^{\circ} \mathrm{C}^{(8,9)}$. The slightly higher recrystallization temperature may be due to the $\mathrm{Cd}$ and $\mathrm{As}$ deficiency of the films. This deficlency would have the effects of increasing the disorder of the film "structure" as well as increasing the relative Si content both of which would increase the amorphous film's resistance to atomic rearrangement and thereby recrystallization.

The amorphous film compositions are deficient in As in all cases and also deficient in $\mathrm{Cd}$ in all but two cases. The glass forming region in the Cd-Si-As system does not cover the compositions of the amorphous films. The region is located in a $\mathrm{Si}$ deficient region of the diagram. The maximum glass forming tendency composition is $\mathrm{Cd}_{2} \mathrm{SiAs}_{7}{ }^{(4)}$. This discrepancy Indicates that the films are highly metastable in the amorphous state and are substantially increased in stability on going through the glass to crystalline transition.

\section{Film-Substrate Effects}

Film-substrate effects arise from either of two interactions:

1. Thermal expansion coefficient difference related stresses and otralus.

2. Interdiffusion of film and substrate constituents.

The thermal expansion of CdSiAs, is very 1ikely to be similar to that of $\mathrm{CdGeAs}_{2}$ for which thermal expansion data are available. The expansion of the latter compound is highly anisotroplc with linear expansion in the a direction of $8.3 \times 10^{-6} / \mathrm{K}$ and $0.4 \times 10^{-6} / \mathrm{K}$ in the $\mathrm{c}$ direction $\left(\mathrm{H}=120^{\circ} \mathrm{C}\right)$ ylelding a ratio of almost 21 to $1^{(10)}$. The linear expansion of CdSiAs 2 In the a direction 18 probably compatible with the linear expansions of 7059 glass, Ta metal, Mo metal and stainless steel. The linear expansion of CdSiAs, in the c direction is probably compatible with the linear expansion of fused silica $\left(0.5 \times 10^{-6} / \mathrm{K}\right)$. 
Due to the large differences in thermal expansion coefficient between $\mathrm{CdSHAs}_{2}$ and the substrate materials of this study, varying degrees of cracking were observed. The most notable case of cracking without extensive peel off occurs in f1lms deposited on Ta coated 7059 glass (Figure 9). Films deposited on fused silica exhibit less cracking than films on higher expansion materials. The inhibition of film contraction in the a direction is apparently less deleterious to film integrity than the imposition of contraction in the c direction.

The interdiffusion of film and substrate is a function of heat treatment duration and temperature as well as substrate composition. In the case of a-CdSiAs ${ }_{2}$ on glass substrates the migration of atoms during heat treatment occurs principally within the films allowing time for film crystallization before an appreciable degree of interdiffusion with substrate occurs. The type of substrate has a strong bearing on the rates of diffusion of film and substrate constituents. Oxide glass substrates being more stable than base metal substrates do not interdiffuse with the films as rapidly. This is shown in that a-CdSIAs, films on stainless steel and Mo shim stock are found to diffuse into and react with the substrates at $500^{\circ} \mathrm{C}$. The same type of films on glass do not diffuse and react to a similar extent until heated to temperatures in excess of $620^{\circ} \mathrm{C}\left(800^{\circ} \mathrm{C}\right)$.

In order for heat treatment to effect crystallization of films, the substrate needs to be very stable with rcopect to temperature and the film constituents. Steel and Ta shim stock do not fulfill this requirement. Class fulfills the requirements very well while Ta coated glass meets the requirement moderately well.

The extension of heat treatment times from 6 hours to one week or more reveals that the Ta coating diffuses into the $\mathrm{CdSiAs}_{2}$ film and that 
a relatively small amount of interdiffusion followed by oxidation of As occurs for $\mathrm{CdSIAs}_{2}$ on glass. The glass constituents do not diffuse into the $\mathrm{CdSIAs}_{2}$ as much as do the Ta, but the $\mathrm{x}$-ray diffraction evidence of diffusion/reaction products indicates that they were also mobile at $500^{\circ} \mathrm{C}$. Larger grain size is found in films on glass. This was due to the fact that diffusion of Ta inhibits grain growth.

Effect of Heat Treatment on Film Composition

The clustering of heat treated film compositions ill a region of Cd and As defiriency (with respect to otoichiometric CuSLAs, ${ }_{2}$ ) is shown in Figure 11. The projection of these points onto the $\mathrm{Cd}_{3} \mathrm{As}_{2}-\mathrm{CdSiAs}_{2}$ and the CdSiAs $_{2}$-SiAs pseudobinary lines is shown in Figure 12.

The points are shown to exist in a region lyiug between $\mathrm{Cd}_{3} \mathrm{As}_{2}$, $\mathrm{CdSIAs}_{2}$ and SiAs. The films all have the CdSiAs 2 crystal structure as determined by $x$-ray diffraction. This indicates that the films are solid solutions of either $\mathrm{Cd}_{3} \mathrm{As}_{2}$ or SiAs in $\mathrm{CdSiAs}_{2}$. This is not surprising in view of the fact that complete solid solution has bcen found in the system $\mathrm{CdSIAs}_{2}-\mathrm{ZnSIAs}_{2}{ }^{(11)}$. Similar findings in related II-IV-V $\mathrm{V}_{2}$ compounds aind systems have been made $(12,13)$. A large solid solubility of Ge in $\mathrm{ZnGeAs}_{2}$ has been found ${ }^{(14)}$. Both $\mathrm{CdGeP}_{2}$ and $\mathrm{CdGeAs}_{2}$ are reported to have large homogenefty regions ${ }^{(14)}$. Up to $20 \%$ solid solubility of InAs in ZnGeAs? (chalcopyrite structure) has been determined ${ }^{(15)}, \mathrm{ZnGeAs}_{2}$ also dissolves In İnAs (zincblende structure) to a great extent (approximately $80 \%$ (15). $\mathrm{znSnAs}_{2}$ and InAs form solid solutions in all proportions ${ }^{(16)} \cdot \mathrm{CdSnAs}_{2}$ and InAs also form solid solutions for all compositions (14). About 50 mol\% InAs was found to bring about transition from chalcopyrite to zincblende structure ${ }^{(17)}$. These findings show the simflarity of $\mathrm{CdSIAs}_{2}$ to other chalcopyrite semiconductors in this regard. 


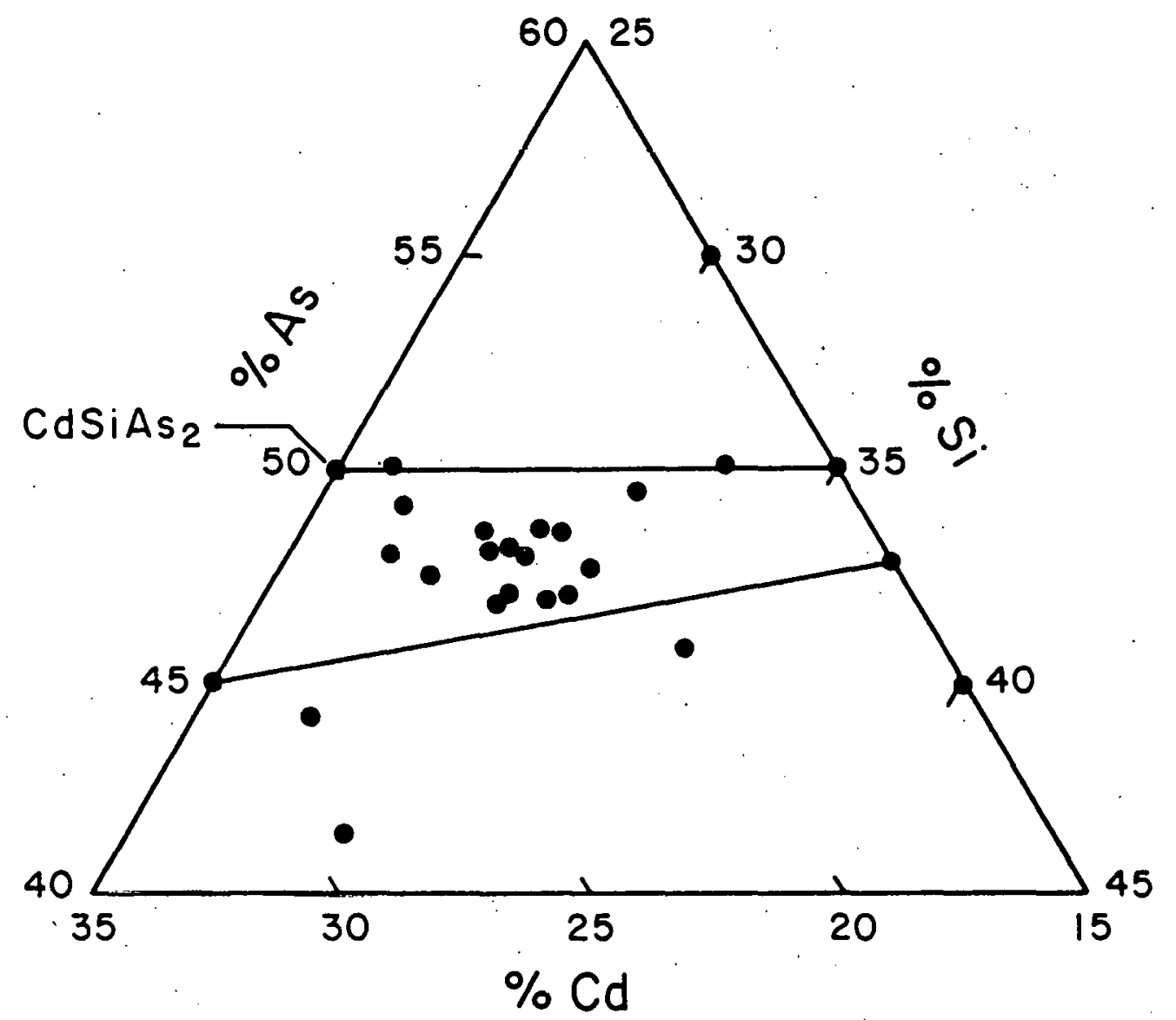

Figure 11. Diagram of the Cd-Si-As System (Limited in Composition to. the Compositions Near t.n CdSiAs? With Either $C d$ and As Deficiencies or Both) Showing Compositions of Crystalline, Non-Stoichiometric CdSiAs 2 Thin Films 


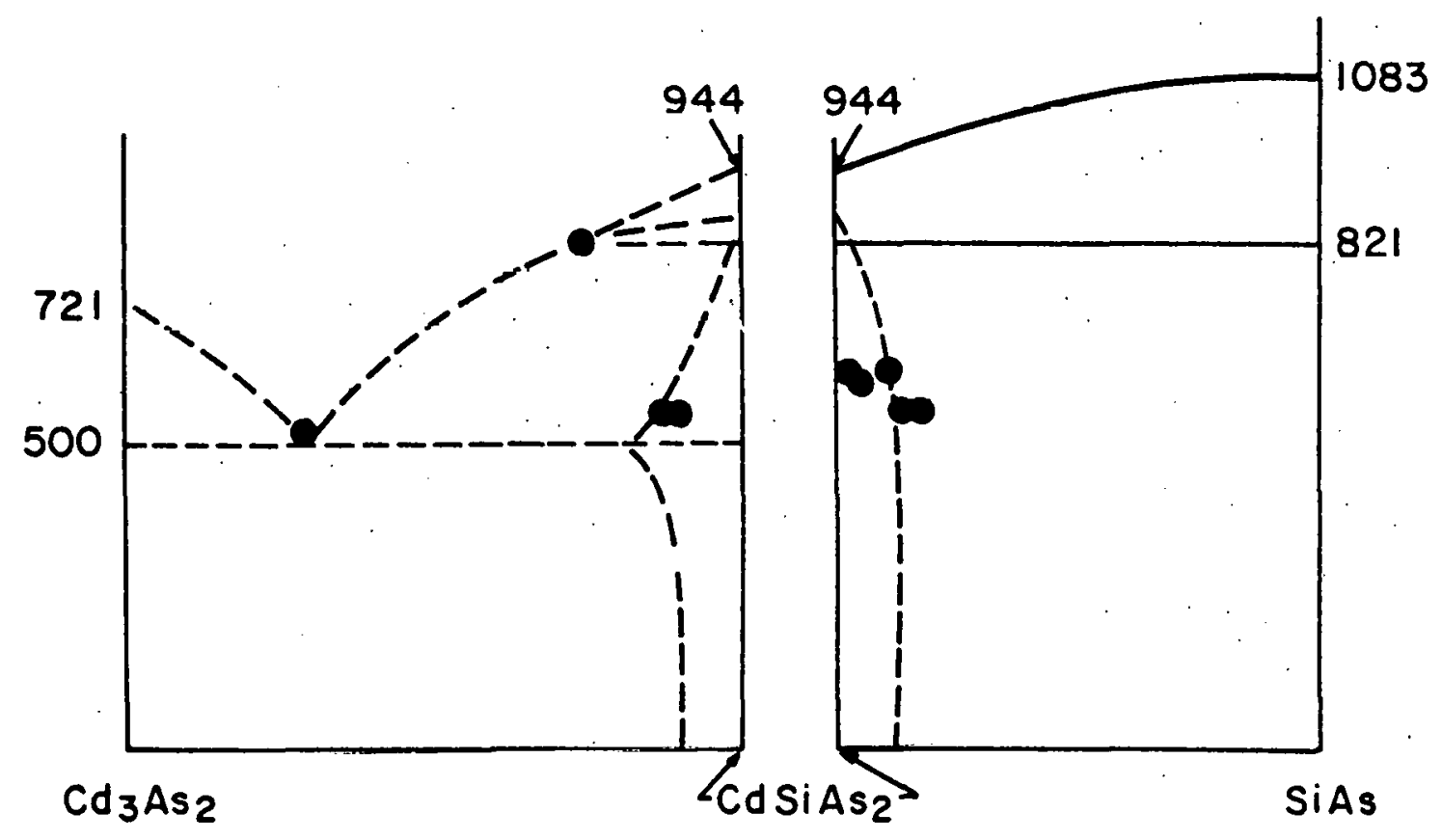

Figure 12. Pseudobinary Phase Diagram of the $\mathrm{Cd}_{3} \mathrm{As}_{2}-\mathrm{CdSiAs} 2$ and CdSiAs2-SiAs Joins Showing Ohserved CdSiAs 2 Solid Solution 
The heat treated films had the chalcopyrite structure of $\mathrm{CdSiAs}_{2}$ and were deficient in $\mathrm{Cd}$ and As due to the fact that the equilibrium vapor pressures of $\mathrm{Cd}$ and $\mathrm{As}_{4}$ over the compound were not sufficiently reduced by the presence of $\mathrm{CdAs}_{2}$ in the heat treatment ampoule.

This preparation method can be used successfully for the fabrication of homogeneous, crystalline CdSiAs, thin films that are nearly stolchiometric.

Models Describing Film Growth

The events occurring during sputter deposition of a-CdSiAs films $_{2}$ determine film composition, structure, and properties. Film composition can vary over an unrestricted range in the case of amorphous sputtered films. There is no stoichiometric selection process in effect during film deposition.

Amorphous film composition is determined by the. impingement ratios of $\mathrm{Cd}, \mathrm{Si}$ and As as well as by short range ordering of atoms into a random network of tetrahedra lacking long range periodicity (Figure 13). The different bond strengths of $\mathrm{Cd}$ to As and Si to As lead to different sticking/ re-emission probabilities: The $\mathrm{Si}$-As bond is stronger than the $\mathrm{Cd}-\mathrm{As}$ bond as reflected in the melting points of $\mathrm{SIAs}_{2}$ and $\mathrm{CdAs}{ }_{2}$ which are $944^{\circ} \mathrm{C}$ and $621^{\circ} \mathrm{C}$ respectively.

The stolchiometric composition is to be expected for films grown during spulleslug of carget HEX $C$ at 100 watts rf power, as the impingement ratio of CdAs $\mathrm{Cos}_{2}$ to is close to thestolchiometric ratio.. The ulserved f1lm compositions are generally deficient in $\mathrm{Cd}$ and $\Lambda_{0}$. The discrepancy 1ndi-: cates that not all of the $C d$ and $A s$ remain in the fllm after arriving from the target. The loss of these film constituents is efther occurring by backscattering or by re-emission processes. The end result is the same. 
(a)

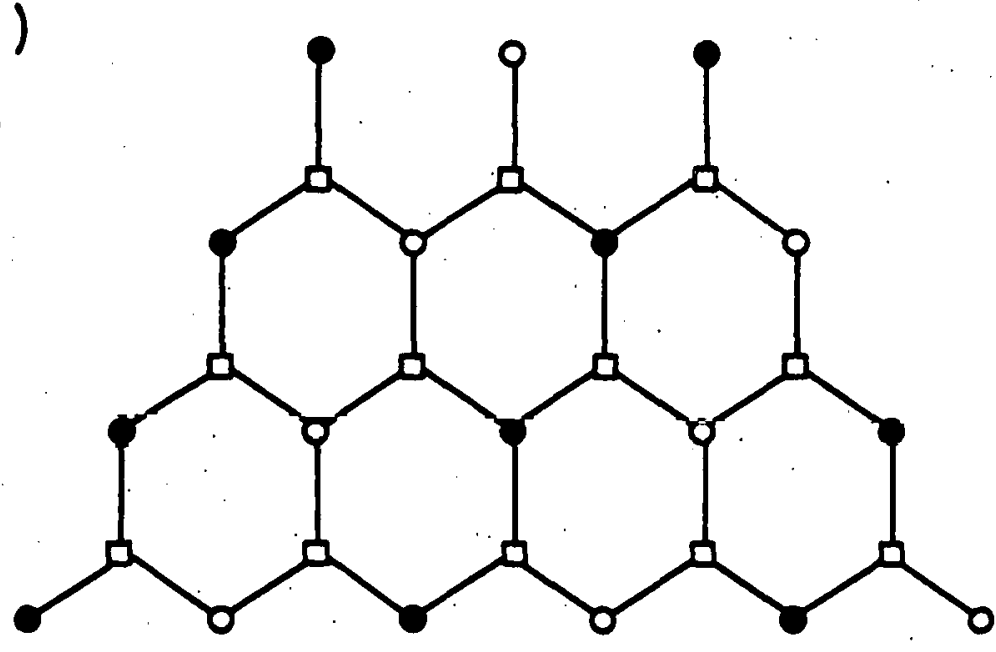

(b)

- Cd

- As

O Si

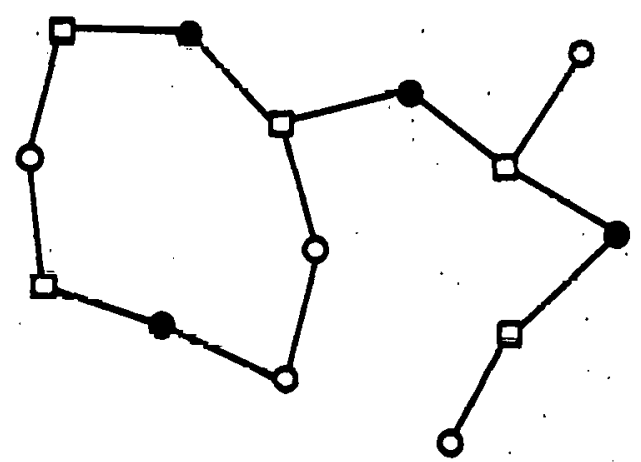

F1gure 13. Schematic Drawing of the (112) Plane of CdS1As 2 and a-CdStAs 2 
Two models are formulated to further describe the loss of Cd and As and to relate losses to $\mathrm{f} 1 \mathrm{~m}$ composition. The first model assumes that only Cd is lost from the growing film after arriving at the substrate. The As loss is assumed to be negligible. The second model assumes that both $\mathrm{Cd}$ and As are lost from the growing film after arriving at the substrate and that the re-emitted $C d$ is replaced by $S 1$ and $C d$ in equal quantities.

Comparison of the calculated results for each model with actual film compositions shows which set of deposition events is more likely to occur. In the following discussion, models are described, assumptions are stated, relationships of materlal losses to film compositions are derived, and film compositions are calculated for comparison purposes.

Model A

To begin modeling the sputter deposition process, the most simple set of conditions are assumed to hold. Since Cd content was found very low. with respect to that of stolchiometric $\mathrm{CdSIAs}_{2}$, it is assumed that deviations in film composition from the "stolchiometric" composition are due to Cd losses alone. Relative Increases in $\mathrm{SI}$ and As result. Normal1zation to $100 \%$ is used as a basts for comparison to observed results. The assumption 1 s also made that $\mathrm{Cd}, \mathrm{S} 1$ and As are sputtered from the target In the ratio $1: 1: 2$.

The obfective of the model is description of the relative increase in $S 1$ and As and decrease in Cd resulting from the loss of a quantity of Cd designated as " $\mathrm{X}$ ".

The assumptions made are:

1. Cd, $S 1$ and $A s$ are sputtered from the target in the rat10 $1: 1: 2$. and arrive at the substrate surface in that rat1o.

2. The sticking coefficient of both $S 1$ and $A s$ is 1 . 
3. There is no re-emission of either $\mathrm{Si}$ or As.

4. Cd is re-emitted/backscattered in quantity $x$.

The calculation of normalized film.compositions is discussed in detail elsewhere ${ }^{(18)}$.

The conclusions made from this model are:

1. The decrease in $\mathrm{Cd}$ is equal to the sum of the increases in Si and As.

2. The increase in As is twice that of Si.

Some possible events unaccounted for in the simple model are:

1. A loss of As on or after arrival at the substrate.

2. Substitution of $\mathrm{SI}$ for Cd on a vacated $\mathrm{Cd}$ site.

The second event makes mention of a Cd site. This refers to the concept already mentioned of short range ordering of two $\mathrm{Cd}$ atoms and two $\mathrm{S} I$ atoms (the "cations") around an As atom (the "anion") in a network of tetrahedra (Figure 13). The network is not very ordered as is crystalline CdS 1 As $_{2}$ such that a Si atom substituting for Cd would not need to overcome large energy barriers. Short range order would inhibit As from substituting for Cd in that As would then be bonded adjacent to another As atom.

The amount of $\mathrm{Si}$ substituting for $\mathrm{Cd}$ can be approximated by assuming that one half of the $x$ vacated Cd sites are filled with $S i$ and the other half with $C d$, due to equivalent influxes. If the Cd re-emission occurs a second time with $\frac{1}{2} \times$ Cd loss, $\frac{1}{2}\left(\frac{1}{2} x\right)$ sites are replaced with $S i$ and the remaining $\frac{1}{4} \times$ with $C d$. With sufficient time for many iterations to occur, the $\mathrm{x}$ Cd sites would be filled with Si: The time available for the iteration of the process is limited.

One can consider Figure 13 as a top view of the 112 plane of a growing film in an ideal crystal. Soon after a Cd atom is re-emitted from the film surface it is replaced by a SI or Cd atom: Arsenic atoms are condensing as 
the nearest neighbors to the row of cations in which the $\mathrm{Cd}$ is located. The time available for the Cd site to be vacated and refilled is limited to the time in which a newly condensed As "covers" it. Since the arrival rate of As is nearly equal to twice that of $\mathrm{Cd}$ and $\mathrm{Si}$, the re-emission/replacement process would be limited to one event per site.

Model B

A second model can be constructed to describe the relative changes in $\mathrm{Cd}, \mathrm{Si}$ and As contents resulting from As and Cd loss with partial replacement of $\mathrm{Cd}$ by $\mathrm{Si}$. The model is based on the following assumptions:

1. $\mathrm{Cd}, \mathrm{Si}$ and $\mathrm{As}$ arrive at the substrate in the ratio $1: 1: 2$.

2. Si sticking coefficient $=1$.

3. Short range ordering occurs in which $\mathrm{Cd}$ and $\mathrm{Si}$ bond only to As, and As bonds only to $\mathrm{Cd}$ and $\mathrm{Si}$.

4. Cd is re-emitted/backscattered in quantity $x$.

5. As is re-emitted/backscattered in quantity $\mathrm{y} ; \mathrm{y}<\mathrm{x}$.

6. Si is not re-emitted.

7. Si replaces $\frac{1}{2}$ of re-emitted $\mathrm{Cd}$.

8. Cd replaces $\frac{1}{2}$ of re-emitted Cd.

9. Interaction of $\mathrm{Cd}$ and As losses is negligible.

The results of this model can be summarized as: (18)

1. The increase of $\mathrm{Si}$ is slightly greater than the decrease of $\mathrm{Cd}$.

2. The decrease in $\mathrm{Cd}$ is greater than that of As by a factor less than $\mathrm{x} / \mathrm{y}$.

Comparison With Actual Observation

The observed \% deviations from the stoichiometric quantities of Cd, Si and As in $\mathrm{CdSiAs}_{2}$ are listed In Table 10 for runs HEX C-9 through HEX C-13 along with the calculated \% deviations for Model A and for Model. B. The observed deviations show that Model A does not describe the actual 
TABLE 10

Average Deviations From Stoichiometric CdSiAs 2 of rf Sputter Deposited a-CdSiAs 2 Films Deposited From HEX C

Target at $r f$ Power $=90$ to 100 Watts

\begin{tabular}{|c|c|c|c|c|c|}
\hline & & $\Delta \%$ & & & \\
\hline & $\mathrm{Cd}$ & $\mathrm{Si}$ & As & $\Delta S i / C d$ & $\Delta \mathrm{As} / \Delta \mathrm{Cd}$ \\
\hline \multicolumn{6}{|l|}{$\underline{\text { Run }}$} \\
\hline 9 & -3.5 & 3.5 & 0 & -1.0 & 0 \\
\hline 10 & -3.5 & 2.2 & 1.3 & -0.6 & -0.4 \\
\hline 11 & -1.6 & 2.8 & -1.2 & -1.8 & 0.8 \\
\hline 12 & -3.1 & 4.6 & -1.6 & -1.5 & 0.5 \\
\hline 13 & 0.2 & 2.2 & -2.4 & 11.0 & -12.0 \\
\hline \multicolumn{6}{|l|}{ Model } \\
\hline $\begin{array}{l}A \\
x\end{array}=2.7$ & -2.1 & 0.7 & 1.4 & -0.3 & -0.7 \\
\hline $\begin{array}{l}B \\
y=2.8 \\
x=2.8 \cdot(2.7)\end{array}$ & -3.1 & 4.6 & -1.4 & -1.5 & 0.5 \\
\hline
\end{tabular}


sputter deposition process. The deviations in As content are most frequently negative. In the one case where the deviation in As content was positive, its magnitude was less than that of $\mathrm{Si}$. The Si deviations were often found to be greater in magnitude than the Cd deviations.

Table 10 lists two calculated results of Model $B$ assuming $x=2.7 \mathrm{y}$ and $y=2 \%$. The assumption of $x=2.7 y$. is based on the fact that the heat of sublimation of As in 2.7 times that of $\mathrm{Cd}$. The tendency for $\mathrm{Cd}$ to be reemitted would therefore be higher than As, and a first approximation to the ratio of their re-emission rates would be the inverse ratio of their heats of sublimation.

Comparison of the observed results with calculated results of Model B accurately describes runs 9,11 and 12 . Run 9 could be described by setting $y$ equal to zero. 


\subsection{Evaporated Films}

The contract began with studies of both sputtered and evaporated films in parallel. Of particular interest was the question of whether stolchiometric CdSiAs ${ }_{2}$ films could be obtained by direct thermal evaporation. This work concentrated on evaporation of the ternary compound ( $\mathrm{CdSiAs}_{2}$ ), followed by studies of a binary. $\left(\mathrm{CdAs}_{2}\right)$. At this point, since feasibility of forming CdSiAs 2 by means of evaporation was not established; only sputtered films were studied further. The $\mathrm{CdSiAs}_{2}$ and $\mathrm{CdAs}_{2}$ thermal evaporation studies are summarized below.

$$
\mathrm{CdS1As}_{2} \text { Evaporation }
$$

The major fraction of the $\mathrm{CdSiAs}_{2}$ evaporation studies were made over the first four months of the contract, and are described in the First Quarterly Rejorl (1).

Although no reports of $\mathrm{CdSiAs}_{2}$ thin films have been found in the literature, some degree of prediction of the ternary thermal behavior may be afforded by a review of the characteristics of the elements and binary compounds in this system. Table 11 is a summary of such data. As indicated, both $C d$ and As are volatile at low temperatures. One might expect similar behavior in the combined state. The vapor pressure trends are, as expected, found to behave as $p($ As $)>p(C d) \gg p(S 1)$ in this system.

Therefore, one might expect that in a non-equilibrium situation, arsentdes in general may decompose with disproportionation. In this case, 
TABLE i1.

PROPERTIES OF SOME COMPOSITIONS IN THE Cd-S1-As TERNARY SYSTEM

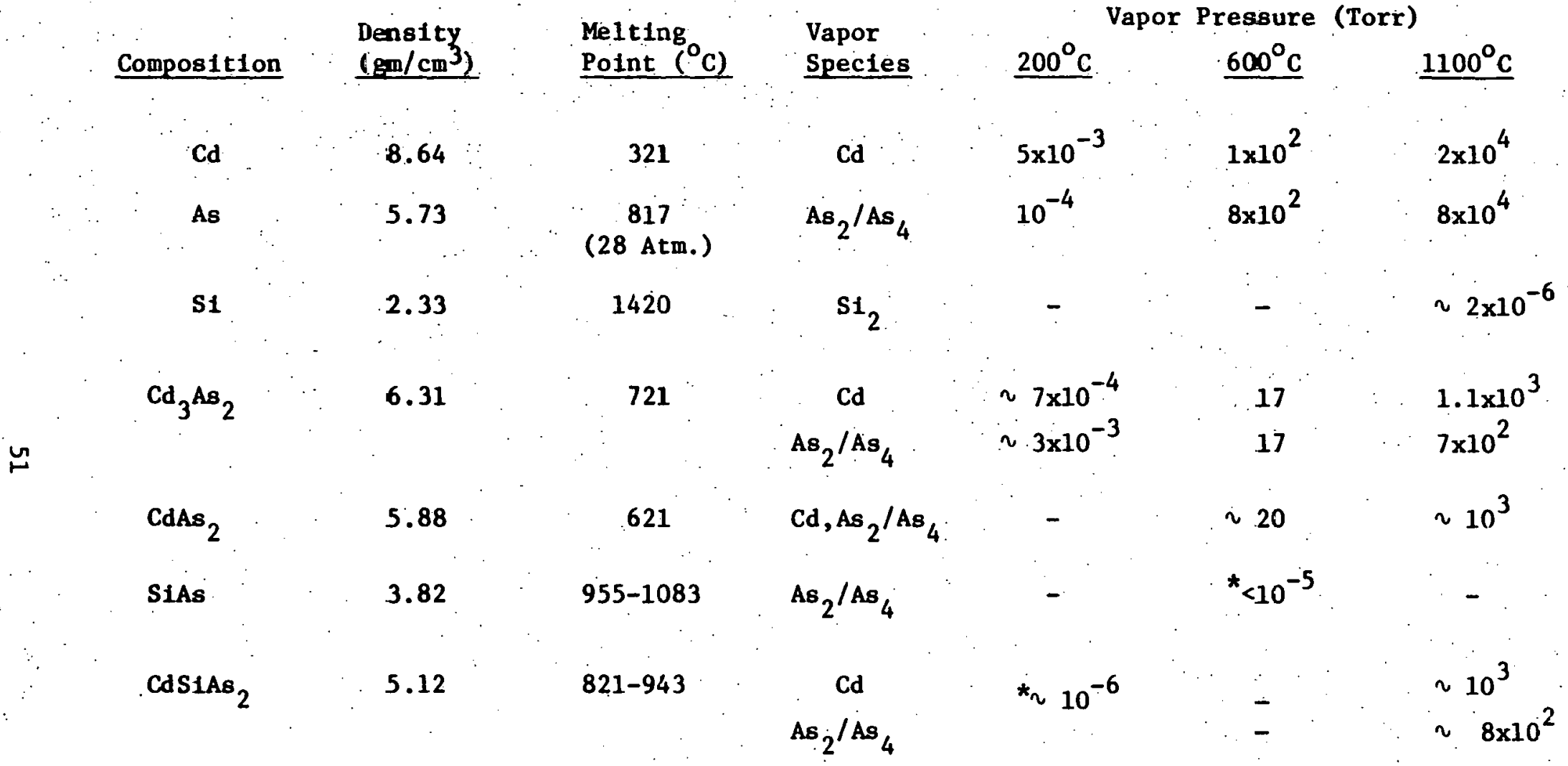

* Suggested by this work 
direct thermal vacuum evaporation should result primarily in evolution of the heavy element species, leaving some form of silicon compound behind.

A simple model for'the evaporation and/or deposition behavior can be developed on the basis of the vapor flux from a simple sphere of the material (19). Evaporations were performed in a Dention DV 503 18" bell jar. system, utilizing a graphite source bottle heated by a Ta element. Source temperature was monftored during the runs using a $\mathrm{Pt}-\mathrm{Pt} / 10 \% \mathrm{Rh}$ thermocouple Imbedded in the source. Four $2.5 \mathrm{~cm} \times 4.5 \mathrm{~cm}$ substrates (glass) were depooited per run. Filn depooition was monitored by a Kronos QM:300 thickness monitor.

To determine the lowest measureable temperature of decomposition, the Inftial vapor effusion as reglstered by the thickness monttor was noted. In two different trials, inftial deposition was noted at about $90^{\circ} \mathrm{C}$ and 0.6 microTorr in the one case, and again at $220^{\circ} \mathrm{C}$ and 15 microTorr in the second Instance. The Indication is that the lower temperature bound for decomposition is strongly dependent on the level of evauation. One might also surmise from this data that oxidation reactions might proceed at rather low temperatures in normal atmospheric ambient. If the deposttion Is directly proportional to the evaporation, and if the evaporation follows this simple model, not being chemically rate-limited, the deposition also ought to follow a trend cublc in the time parameter at any given temperature: The form of the equation for deposition weight gain $\bar{D}$ as a. function of time should then be:

$$
D=a t^{3}+b t^{2}+c t+d
$$

and In this case the coefficlent d may be given the value zero.

In simple evaporation one would expect the evaporation flux to be directly proportional to the vapor pressure, which in turn should follow the 
well-known Clausius-Clapeyron relationship. If the evaporation is not simple, but rather requires a preceding disproportionation, the temperature dependence of evaporation flux should be more complex. Since the deposition flux should be related to the evaporation flux by a constant of proportiona'11ty, the coefficient $c$ above should be directly proportional to the evaporation flux. A plot of $\log c$ against reciprocal temperature should indicate whether the evaporation is simple or complex.

The CdSiAs, material used was prepared as described earlier in this report.

As the evaporation source temperature was increased, the rate of deposition greatly increased. The condensation progress was recorded at varlous steady state source temperature levels in order to estimate the dependence of evaporation and deposition on time and temperature. Some typical results are given in Flgure 14, wh1ch shows as characteristic curvilinear depositfon, as suggested by the previous equation. The data were submitted for computer assisted least squares analysis to find a set of coefficlents giving a good fit to the cublc polynomial expression. These coefficlents are 11sted in Table 12, and the temperature dependence of the coefficient $c$; a deposition flux-related quantity, fis shown in FIgure 15 .

A pintnt-by-polnt check of the expressions gave very good correspondence with the observed data. From Figure 15, it is seen that the deposition flux first increases more rapidly than predicted from the log c agalnst reciprocal temperature relationsh1p, then falls off sharply. The Indication 18, of course, that the mechanism for evaporation is not a simple, direct one.

The behavior might be explained by a process" limited by decomposition. 


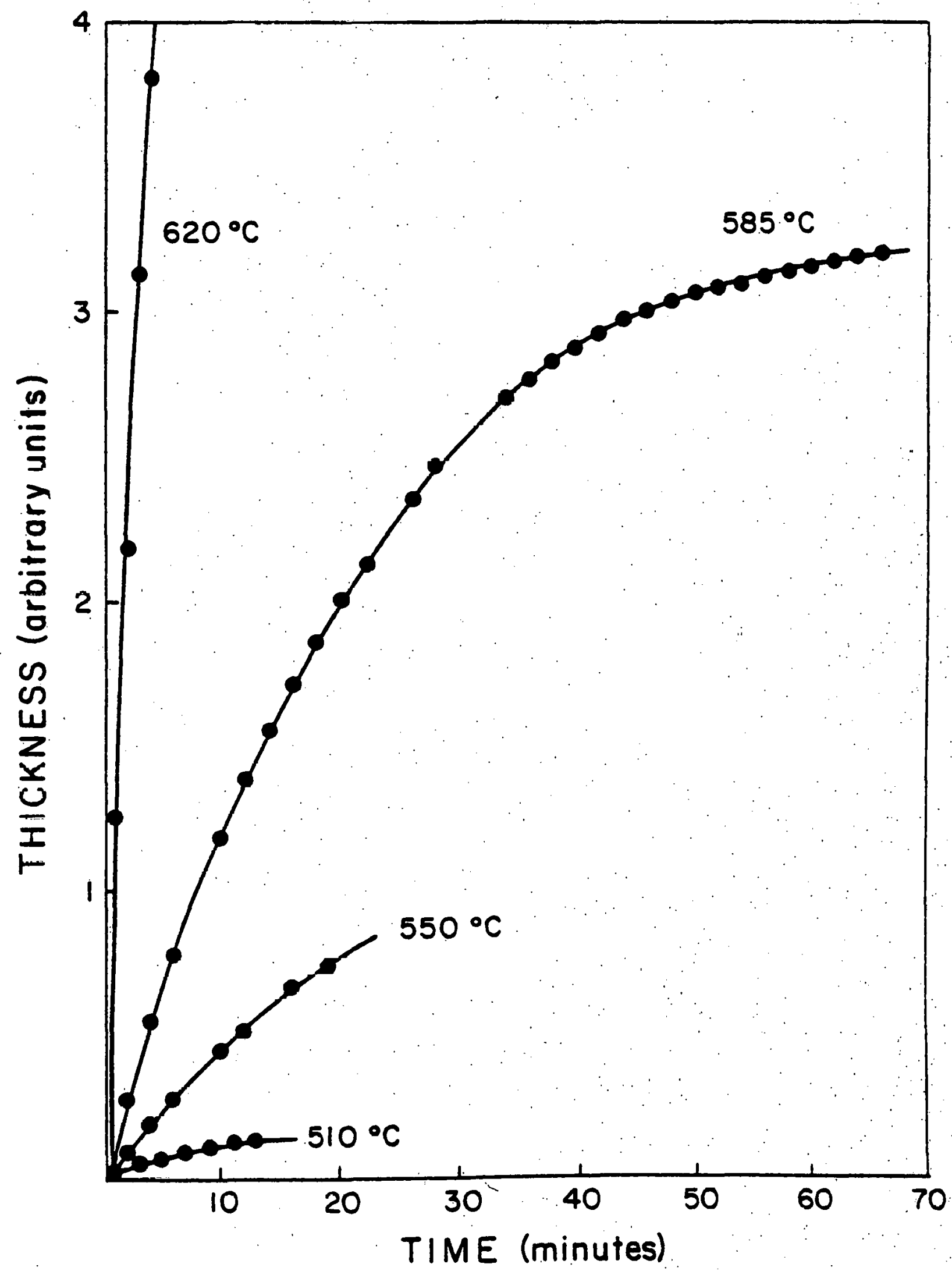

F1g.14 - Deposition Progress of Films Derived from Thermal Decomposition of $\mathrm{CdSLAs}_{2}$.

54 
TABLE 12

COEFFICIENTS FOR BEST LEAST-SQUARES

FIT OF DEPOSITION DATA TO CUBIC EQUATION

\begin{tabular}{|c|c|c|c|c|}
\hline $\begin{array}{c}\text { Temperature } \\
\left({ }^{\circ} \mathrm{C}\right)\end{array}$ & $\operatorname{ax} 10^{5}$ & $b \times 10^{3}$ & $\operatorname{cx} 10^{2}$ & $\mathrm{~d} \times 10^{2}$ \\
\hline 510 & 3.37 & -1.13 & 1.94 & 0.01 \\
\hline 550 & 0.677 & -0.626 & 5.01 & -0.41 \\
\hline 585 & 1.112 & -2.072 & 13.68 & 1.67 \\
\hline 620 & 385.8 & -108.1 & 131.6 & -0.70 \\
\hline 714 & 22.34 & -5.24 & 6.29 & -0.12 \\
\hline 810 & 48.26 & -12.28 & 12.42 & -0.65 \\
\hline 913 & 9.14 & 1.68 & 2.41 & -0.03 \\
\hline
\end{tabular}




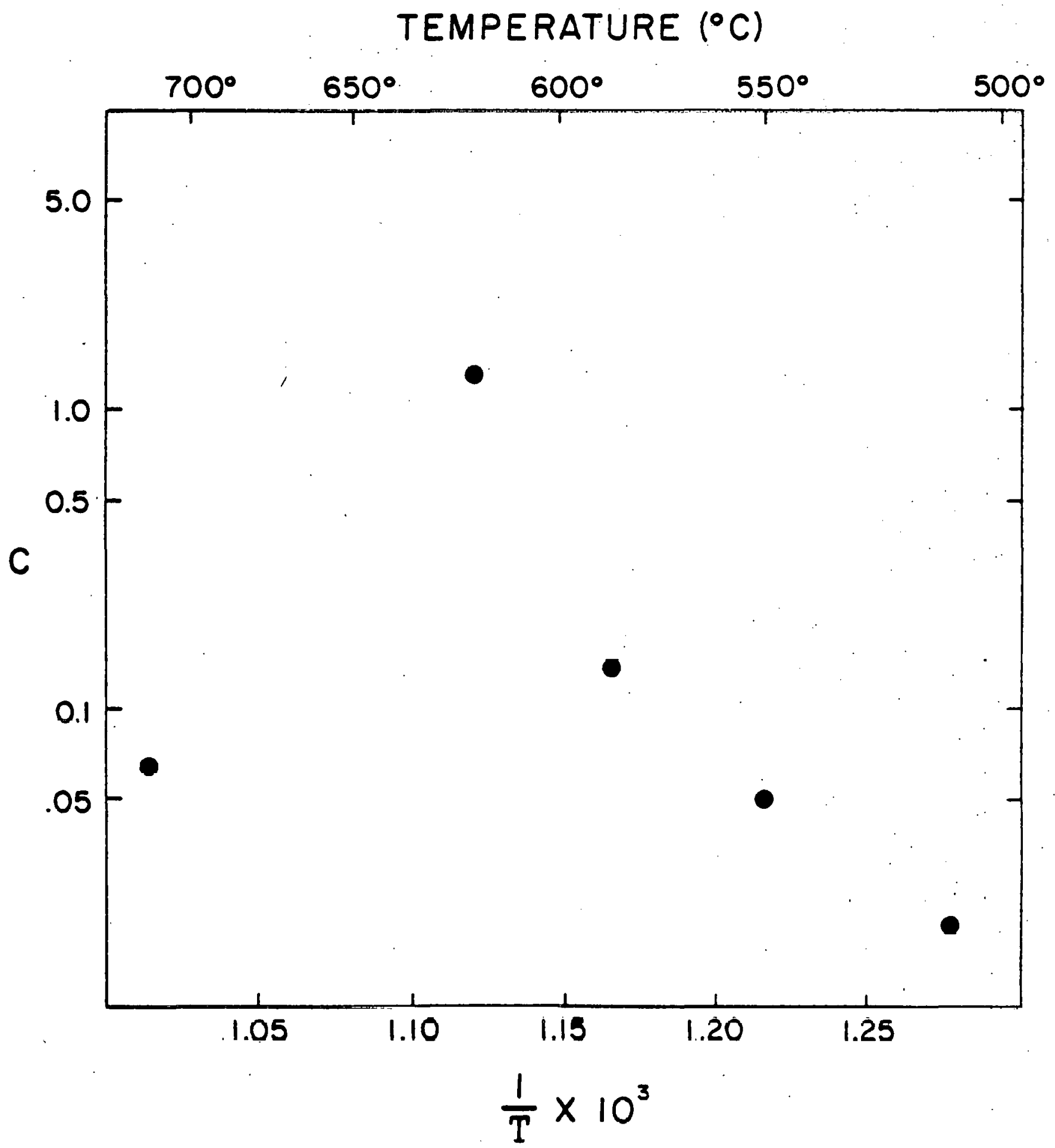

F18.15 - Temperature Dependence of Flux-related Deposition Parameter Coefficient c. 
rate at low temperatures and exhaustion of decomposition products at high temperature, with evaporation rate controlling in the mid temperatures circa $600-650^{\circ} \mathrm{C}$.

Evaporations of the ternary over several heating schedules indicated that the vaporizing spectes are products of the following stepwise decomposition reactions:

$$
\begin{aligned}
& \operatorname{CdSiAs}_{2}(\mathrm{~s}) \quad 570-710^{\circ} \mathrm{C} \\
& \mathrm{SiAs}(\mathrm{s}) \geq 710^{\circ} \mathrm{C} \\
& \mathrm{Si}(\mathrm{s})+\frac{1}{4} \mathrm{As}_{4}(\mathrm{~g})
\end{aligned}
$$

Fllms as well as source residue were analyzed by $x$-ray diffraction, electron microprobe and SEM methods. The major results are shown in Tables 13 and 14. The indications are that $C d$ and $A s$ are initially preferentially evaporated to exhaustion of the Cd, followed by emission of the remaining As. Thus the evidence from the films and residues correlate well and lead to the same conclusions. It should be noted that in no case were any of the resulting films found to have any crystalline structure. The only structure found in x-ray diffraction of the films was the broad, diffuse weak scattering at low angles characteristic of amorphous material. The $x$-ray diffraction analysis of the bottle residues distinguished intensity peaks not attributable to any of the elements or known binaries in the Cd-Si-As ternary system. These peaks were further differentiated in that intensities designated as pattern $A$; and corresponding to lattice spacings of 4.02 and $4.99 \AA$ appeared consistently in all the residues.

Wadsten ${ }^{(20)}$ has studied the thermal decomposition of silicon arsenides and claims to have observed the compound $\mathrm{S}_{6}{ }_{6} \mathrm{As}$ as resulting from heitting of SiAs to $930^{\circ} \mathrm{C}$. While this investigation does not support his findings, 1t was felt that pattern $B$ of Table 13 might arise as such an intermediate phase. However, no correlation was found between the reported pattern for 
TABLE 13

X-RAY DIFFRACTION ANALYSIS OF RESIDUE

FROM CdSIAs, EVAPORATION

\begin{tabular}{|c|c|c|c|c|c|}
\hline \multirow{2}{*}{$\begin{array}{c}\text { Evaporation Source } \\
\text { Temperature }\left({ }^{\circ} \mathrm{C}\right)\end{array}$} & \multicolumn{2}{|c|}{ Diffraction } & \multicolumn{2}{|c|}{ Patterns Identified } & . \\
\hline & $\mathrm{CdSIAs}_{2}$ & S1As & Si & $\mathbf{A}$ & B \\
\hline 570 & $\begin{array}{l}\text { Very } \\
\text { weak }\end{array}$ & Strong & - & Trace & $\begin{array}{r}\text { Very } \\
\text { weak }\end{array}$ \\
\hline 619 & Trace & Serong & $\begin{array}{l}\text { Very } \\
\text { weak }\end{array}$ & Trace & Weak \\
\hline 712 & - & Serong & Weak & $\begin{array}{l}\text { Very } \\
\text { weak }\end{array}$ & Weak \\
\hline 812 & - & Weak & Strong & Weak & - \\
\hline 912 & - & - & Strong & Weak & - \\
\hline 1010 & - & - & Strong & Weak & - \\
\hline
\end{tabular}


TABLE 14

ELECTRON MICROPROBE ANALYSIS OF EVAPORATED FILMS

\begin{tabular}{|c|c|c|c|c|}
\hline \multirow{2}{*}{$\begin{array}{l}\text { Source Peak } \\
\left.\text { Temp ( }{ }^{\circ} \mathrm{C}\right)\end{array}$} & \multicolumn{4}{|c|}{ Film Composition (At. \%) } \\
\hline & $\underline{\mathrm{Cd}}$ & As & $\underline{\underline{s i}}$ & $\mathrm{Cd} / \mathrm{As}$ \\
\hline 570 & 37.4 & 62.5 & 0.2 & 0.60 \\
\hline & $\therefore$ & & . & \\
\hline 618 & 41.3 & 58.5 & 0.2 & 0.71 \\
\hline 713 & 27.1 & 72.8 & 0.1 & 0.38 \\
\hline 812 & 4.0 & 95.2 & 0.8 & 0.04 \\
\hline 1010 & 2.1 & $95: 5$ & 2.4 & 0.02 \\
\hline
\end{tabular}


$S i_{6}$ As and pattern $B$.

It is clear that the decomposition in vacuum of the ternary compound $\mathrm{CdSIAs}_{2}$ proceeds in a stepwise fashion to produce fịst silicon arsenide, then silicon at a higher temperature. This behavior precludes the formation of homogeneous thin ternary CdS1As, films by direct evaporation, since such films would inevitably be sharply graded in composition, and perhaps nonstoichiometric in the averaged composition due to other deposition-related effects.

The evaporation/deposition seems to follow the predicted cubic law, but Is not simple. From the low temperature volatility, one might expect elther that oxldation may occur readily under amblent atmospherlc conditions, or that such oxtdation had already occurred with the powders used. $\mathrm{CdAs}_{2}$ Evaporation

Following the CdSIAs ${ }_{2}$ evaporation study, a study of CdAs ${ }_{2}$ evaporation was Inftiated. The objective was to determine if a dual effusion setup; composed of $\mathrm{CdAs}_{2}+\mathrm{S} 1$ sources would be feastble. Due to the preferential effusion of $\mathrm{Cd}$ and As species from the $\mathrm{CdAs}_{2}$ charge, the above technique 1s not feastble. The situation could possibly be rectifled by modifying the Cd-As charge composition - however due to time constraints this was not attempted.

The $\mathrm{CdAs}_{2}$ study was described in some detali in the Second Quarterly Report, Including a model for the decomposition and evaporation process. For runs performed at several source temperatures, all films were Cd defictent ${ }^{(21)}$. This is seen in Figure 16 .

One posstble gross remedy for the non-stolchiometry problem would be to use a physical mixture of $\mathrm{CdAs}_{2}$ and $\mathrm{Cd}_{3} \mathrm{As}_{2}$ powders as evaporation sources, 


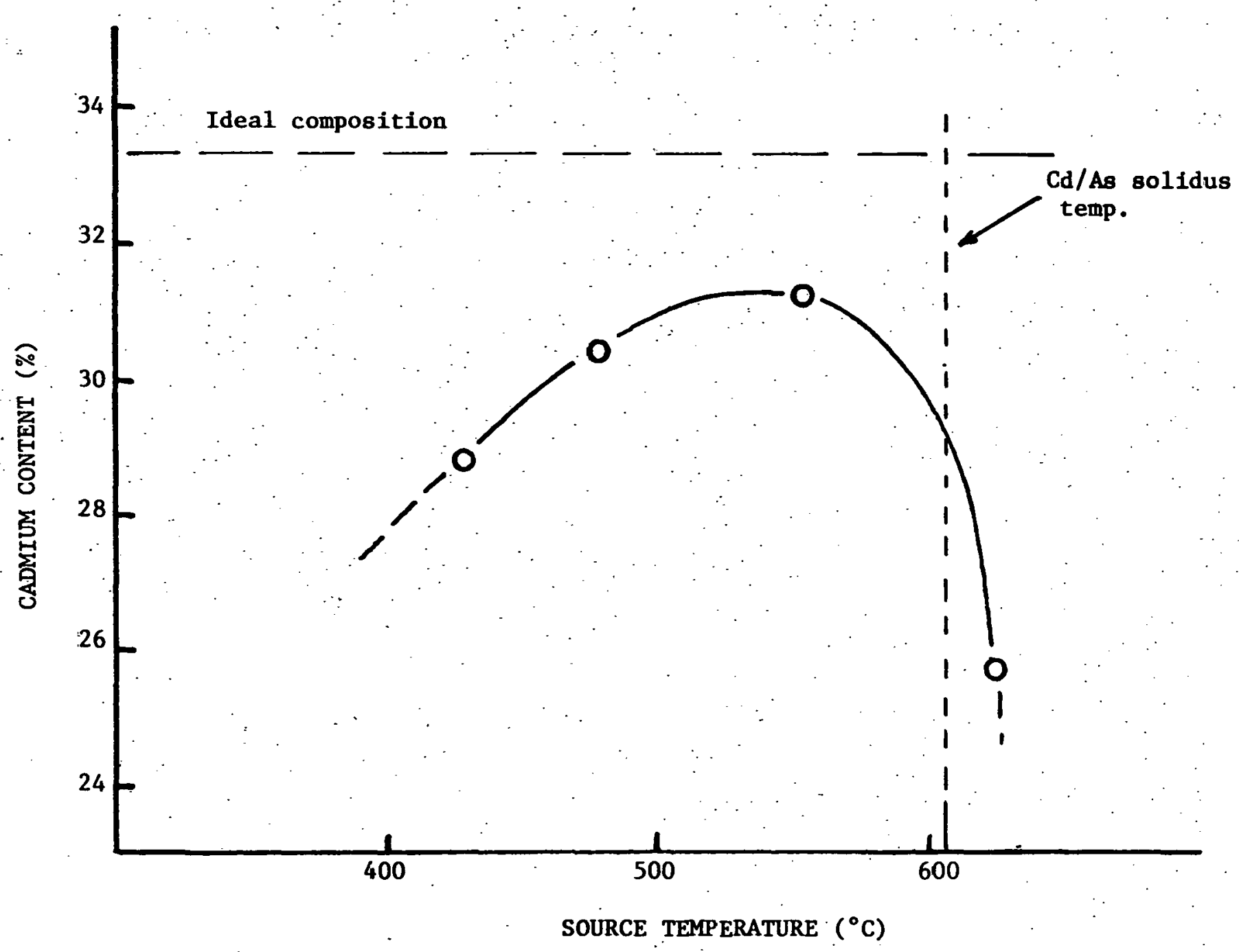

Figure 16. Cd-As film composition as a function of evaporation sourze temperature. 
with enough $\mathrm{Cd}_{3} \mathrm{As}_{2}$ admixture to enrich the cadmium content of the film to achieve an apparent overall $\mathrm{Cd} /$ As ratio of $1: 2$. "However, this would probably not satisfy the chemistry requirements on a microscale without postevaporation treatment. In any case, $x$-ray data indicate the necessity of post deposition heat treatment to develop crystallinity.

The evaporation of $\mathrm{CdAs}_{2}$ seems to follow a polynomial time dependence and a semilogarithmic temperature dependence. During evaporation, the $\mathrm{CdAs}_{2}$ partially decomposed to a $\mathrm{CdAs}_{3} \alpha^{\prime \prime}$ phase and a third phase, as well as probably firee arsentc.

From these general resilits, it was concluded that the direct formation of crystalline CdSiAs, thin films by co-evaporation of Cd/As material and $\mathrm{Si}$ from separate sources was not practical with the time and equipment restraints at hand.

\subsection{Heterojunction Fabrication}

Two types of preliminary junctions were fabricated. The first was with evaporated CdS on cut and polished bulk polycrystalline CdSiAs ${ }_{2}$ (plus other minor phases), and the second was with evaporated CdS on heat treated CdSiAs $_{2}$ films.

For the first type, bulk $\mathrm{CdSiAs}_{2}$ sections were cut from ingots with a diamond saw, mounted onto a 2 "x1" $x^{\frac{1}{4}}$ " copper plate with conducting epoxy, ground via SIC and polished successively with $1.0,0.1$ and $0.05 \mu \mathrm{m} \mathrm{Al}_{2} \mathrm{O}_{3}$ powder/slurry.

CdS was then sublimed onto this surface, which was maintained at $300^{\circ} \mathrm{C}$. Only a few of these were formed. Contact was made to the CdS by means of an In dot $(0.5 \mathrm{~mm})$ pressed onto the surface.

An open clrcuit voltage of over $200 \mathrm{mv}$ was measured for one of the 
devices, at a current of about $3.4 \mu \mathrm{A}$. This device was series resistance limited, as indicated in the $I-V$ curves of Figure 17 . This is attributed mainly to the dot contact, but also to the thin CdS layer $(</ \mu \mathrm{m})$. The device degraded with subsequent heat treatments, but the feasibility of a rectifying, photogenerating junction was established.

Some $\mathrm{CdSIAs}_{2}$ heat treated films were used to form.CdS/CdSiAs ${ }_{2}$ junctions. These junctions should be viewed as very preliminary ones, due mainly to the non-optimized film properties (as described earlier). CdS was sublimed onto the CdSiAs ${ }_{2}$ film, which was on a Ta/glass substrate. Rectifying behavior was observed, although with no measurable photoresponse. An I-V characteristic is shown in Figure 18.

Even though the photoresponses measured for the very few bulk and thin film cells that were fabricated were not large, the results are encouraging In that rectifying behavior is obtained with CdS and a measurable photoresponse was obtained. This is encouraging in that the bulk $\operatorname{CdSiAs}_{2}$ was porous, brittle and not perfectly homogeneous in composition (i.e. the polished "surface" was still quite rough due to pores). The thin film .. CdSiAs $_{2}$ used for junction fabrication was cracked, non-stoichiometric and had very small grains. Thus, drastic increases in photoresponse are expected as the $\mathrm{CdSIAs}_{2}$ is improved. 


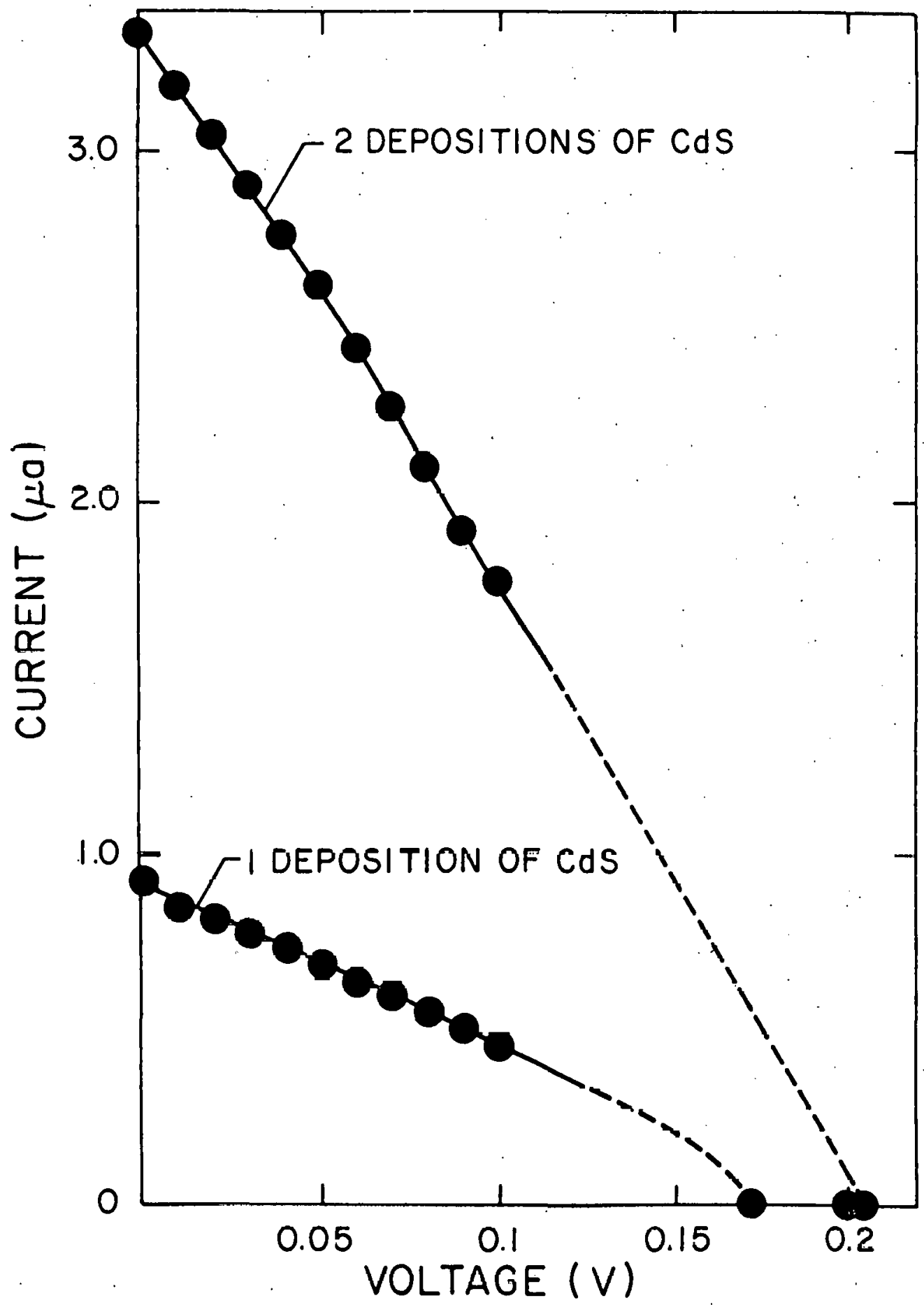

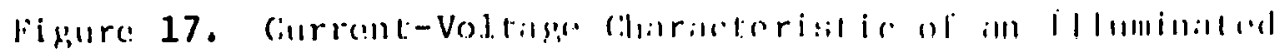

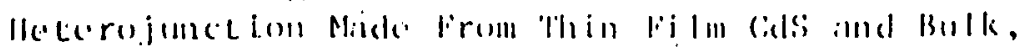
l'olycrystal.1ine CdSiAs 2 , Run 52 , Showing

Photoresponse 


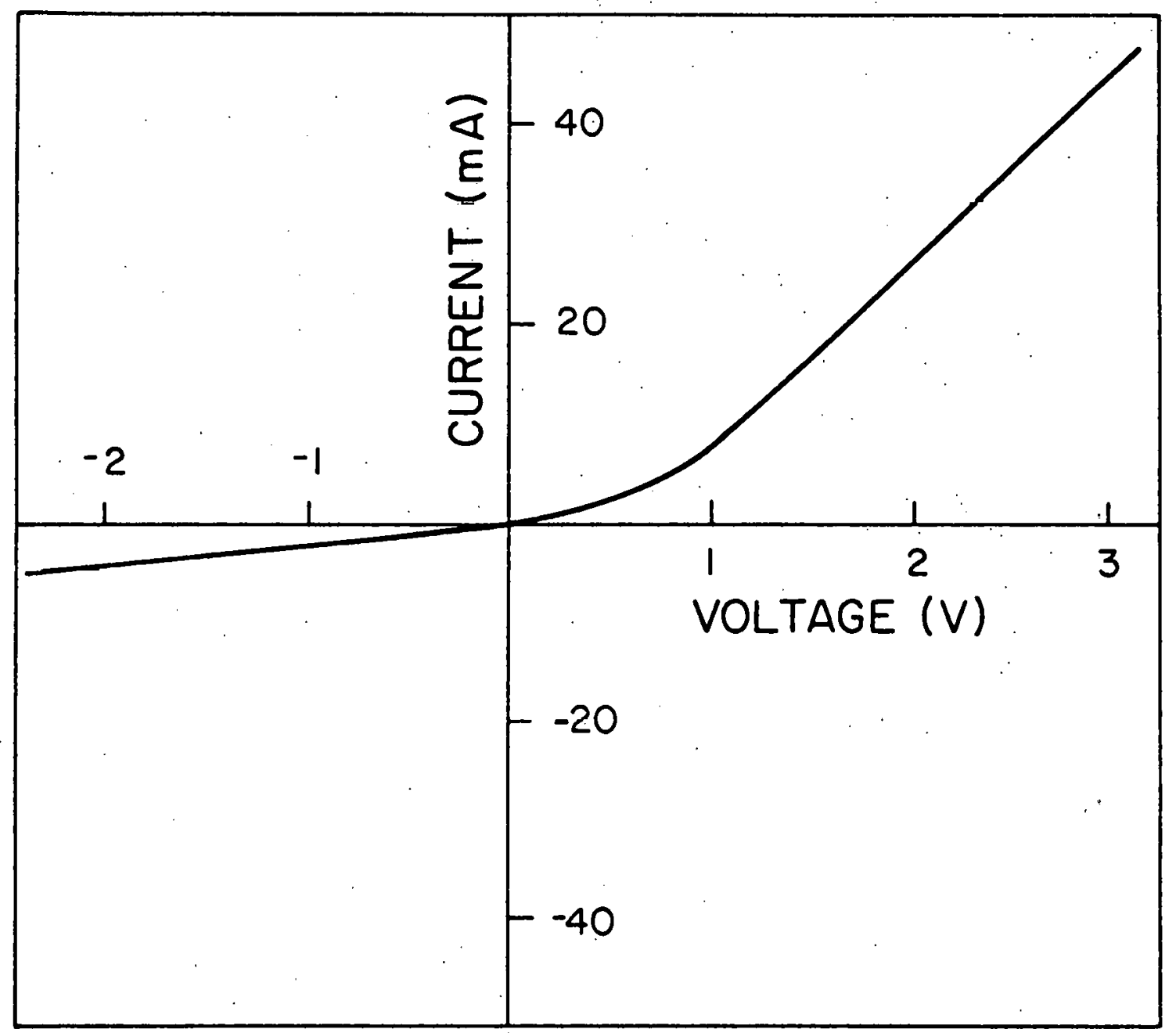

Figure 18. Current-Voltage Characteristic of a CdS/CdSiAs, Thin Film Heterojunction 


\section{REFERENCES}

1. Progress Report DOE/ET/23007-1, VPI\&SU (Juiy 1979).

2. J. N. Hartley and W. T. Pawlewicz, Proceedings of DOE Photovoltaics Program Semi-Annual Review, October 1977 (p. 83).

3. DOE Contract No. DE-AC04-79ET23007, Exhibit A, Statement of Work $(4 / 9 / 79)$.

4. J. Houserova and A. Hruby, Czech. J. Phys. B22, 861 (1972).

5. L. I. Maissel and R. Glang, eds., Handbook of Thin Film Technology, McGraw-Hill (1970).

6. V. K. Yarmarkin et a1, Phys. Stat. Sol. 48, 129 (1971).

7. M. T. Dimutriu, Rev. Roum. Phys. 20; 547 (1975).

8. V. D. Prochukhan and Y. V. Rud, Sov. Phys. Semicon. 12, 121 (1978).

9. A. S. Borshchevskii et al, Sov. Phys. Semicon. 10, 74 (1976).

10. H. Kildal, Ph.D. Thesis, Stanford University, Technical Report AFMLTR-72-77, Wright Patterson AFB, Ohio (1972).

11. A. M. Joullie et al, Sol. State Comm. 19, 369 (1976).

12. J. L. Shay and J. H. Wernick, l'ernary Chalcopyrite Semiconductoris: Growth, Electronic Properc1es and Applicar1ons, Pargamon Press (1975)

13. M. J. Bernard, De Physlyue 36, C3=1 (197j).

14. A. S. Borshchevski1 et al, Phys. Stat. Sol. $21,9(1967)$.

15. G. Giesecke and H. Pfister, Acta Crystall. 14, 1289 (1961).

16. H. Borchers and R. G. Maler, Metallurg. 8, 775 (1963).

17. N. A. Goryunova and V. D. Prochukhan, Sov. Phys.- Sol. State 2, 161 (1960).

18. A. F. Carroll, Ph.D. Thesis, VPI\&SU, May 1980 (Appendix B).

19. C. F. Smith, L. C. Burton, A. F. Carroll and L. H. S1ack, to appear in Thermochimica Acta (1980).

20. T. Wadsten, Thermochimica Acta 21,285 (1977).

21. Progress Report DOE/ET/23007-2, VPI\&SU, October 1979. 


\section{RESEARCH CONTRIBUTORS}

Dr. L. C. Burton, Principal Investigator, Assoc. Prof. of Electrical Engineering.

Dr. L. H. Slack, Co-Principal Investigator, Assoc. Prof. of Materials Engineering.

Dr. C. F. Smith, Research Associate.

Mr. A. F. Carrol1, Graduate Research Assistant.

Mr. H. Naseem, Graduate Research Assistant.

Mr. T. Solberg, Research Assoclate.

Mr. F. D. Mitsianis, Instrument Supervisor.

Mr. E. Cannon, Undergraduate Assistant.

Mr. S. Fischer, Undergraduate Assistant.

Mr. A. Campagnola, Undergraduate Work-Study. 